DR LAURA INES GARAY (Orcid ID : 0000-0003-2929-6346)

PROFESSOR ALEJANDRO F DE NICOLA (Orcid ID : 0000-0002-3523-9148)

Article type : Original Article

\title{
CHANGES IN NEUROSTEROIDOGENESIS DURING DEMYELINATION AND REMYELINATION IN CUPRIZONE TREATED MICE
}

\author{
María Luz Leicaj ${ }^{a}$, Laura Pasquini ${ }^{b}$, Analia Lima ${ }^{a}$, M.Claudia Gonzalez Deniselle ${ }^{a}$ d Juana Maria \\ Pasquini ${ }^{b}$, Alejandro F. De Nicola ${ }^{a, c}$ and Laura I. Garay ${ }^{a, c}$ \\ aLaboratory of Neuroendocrine Biochemistry, Instituto de Biologia y Medicina Experimental and \\ National Research Council (CONICET), Obligado 2490, 1428 Buenos Aires, Argentina. \\ ${ }^{b}$ Department of Biological Chemistry, School of Pharmacy and Biochemistry, Institute of \\ Chemistry and Biological Physicochemistry (IQUIFIB), University of Buenos Aires and \\ National Research Council (CONICET), Argentina \\ ${ }^{\mathrm{C} D e p a r t m e n t}$ of Human Biochemistry and \\ ${ }^{\mathrm{d} D e p a r t m e n t}$ of Physiological Sciences, University of Buenos Aires, Paraguay 2155, 1121 Buenos \\ Aires, Argentina
}

RUNNING TITLE: neurosteroidogenesis in cuprizone de/remyelination

This article has been accepted for publication and undergone full peer review but has not been through the copyediting, typesetting, pagination and proofreading process, which may lead to differences between this version and the Version of Record. Please cite this article as doi: 10.1111/jne. 12649

This article is protected by copyright. All rights reserved. 
*Corresponding author at Instituto de Biologia y Medicina Experimental, Obligado 2490, 1428 Buenos Aires, Argentina. Email address: laurainesgaray@gmail.com

Abbreviations: ALLO: allopregnanolone; CC1: anti-adenomatous polyposis coli clone CC1; CD11b: cluster of differentiation molecule 11B; CPZ : cuprizone ; DHP : dihydroprogesterone; EAE : experimental autoimmune encephalomyelitis; IBA1: ionizing calcium -binding adapter molecule 1 ,

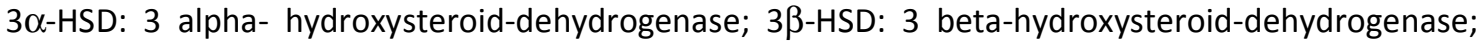
MBP: myelin basic protein; MS : multiple sclerosis; NF-KB: nuclear factor kappa B; OPCs:oligodendrocyte progenitor cells; PR : progesterone receptor; PROG : progesterone; THP : tetrahydroprogesterone; 4; TNF $\alpha$ : tumor necrosis factor alpha; TNFR1: tumor necrosis receptor type 1 Receptor ; TSPO: mitochondrial translocator protein $18 \mathrm{Kd}$; StAR: steroidogenic acute regulatory protein; VDAC: voltage-dependent anion channel.

\section{ABSTRACT}

Literature evidence indicates that changes of neurosteroids may be involved in the pathophysiology of Multiple Sclerosis (MS). The present study assessed if changes of neurosteroidogenesis also occurred in gray and white matter regions of the brain from mice subjected to cuprizone-induced demyelination. To this end, we compared the expression of neurosteroidogenic proteins including steroidogenic acute regulatory protein (StAR), voltage-dependent anion channel (VDAC), $18 \mathrm{Kd}$ translocator protein (TSPO), and neurosteroidogenic enzymes including the side chain cleavage

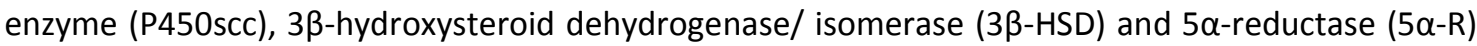
during the demyelination and remyelination periods. Using immunohistochemistry and qPCR, we demonstrated a decreased expression of StAR, P450scc and $5 \alpha-R$ in consonance with an increase astrocytic and microglial reaction and elevated levels of TNF $\alpha$ during the cuprizone demyelination period in hippocampus, cortex and corpus callosum. These parameters as well as the glial reaction were normalized after two weeks of spontaneous remyelination in regions containing gray matter. Conversely, persistent elevated levels of TNFa and low levels of StAR and P450scc were observed during remyelination in corpus callosum white matter. We concluded that neurosteroidogenesis/myelination status and glial reactivity were inversely related in the hippocampus and neocortex. Establishing a cause and effect relationship for the measured variables remains a future challenge to understand the pathophysiology of MS.

This article is protected by copyright. All rights reserved. 
Key words: demyelination, remyelination, neurosteroidogenesis, cuprizone model, microglia

\section{INTRODUCTION}

Multiple sclerosis (MS) is a CNS disease leading to the demyelination of white and gray matter ${ }^{1}$, characterized initially in most patients by relapsing-remitting episodes. MS presents loss of oligodendrocytes, axonal injury, neurodegeneration and inflammation ${ }^{2}, 3$. A role for steroid hormones has been suggested since incidence, progression and severity of MS are affected in a sexdependent manner ${ }^{4}$. Furthermore, the prospective European Pregnancy in Multiple Sclerosis (PRIMS) study has found that the rate of relapse is significantly reduced during the last 3 months of pregnancy, when circulating levels of estrogens and progesterone are highest, while the relapse rate increases during the first 3 months post-partum, coincident with the drop in sex steroid levels ${ }^{5}$. These clinical data suggest that sex steroids might play a beneficial role in this disease. In preclinical model of MS, testosterone, progesterone and estradiol, exert anti-inflammatory, promyelinating and neuroprotective effects, reinforcing a possible therapeutic use for these hormones ${ }^{6-8}$. In this line, we and others have found that progesterone administration to mice with experimental autoimmune encephalomyelitis (EAE), a common model for MS, reduces the clinical scores, the inflammatory response, prevents demyelination and axonal damage in the spinal cord ${ }^{9-12}$. In addition to progesterone, treatment with estrogens reduces the clinical severity of both active and adoptive EAE before or after disease onset. Thus, sex steroids exert beneficial effects for MS as shown in numerous studies ${ }^{7,12,13}$.

It is well documented that the nervous system is capable of synthesizing de novo bioactive steroids from cholesterol. One or more components of neurosteroidogenesis have been found in neurons, oligodendrocytes, astrocytes and microglia ${ }^{14-16}$. The steroid synthesizing machinery involves the steroidogenic acute regulatory protein (StAR), which regulates cholesterol transfer within the mitochondria, and the transport of cholesterol via a channel composed of $18 \mathrm{Kd}$ translocator protein (TSPO), the voltage-dependent anion channel (VDAC) plus some accessory proteins. Inside the mitochondria, the side chain cleavage enzyme (P450scc) converts cholesterol into pregnenolone, which is metabolized to progesterone by $3 \beta$-hydroxysteroid dehydrogenase/ isomerase $(3 \beta-H S D)$. Progesterone is further reduced into dihydroprogesterone (DHP) by $5 \alpha-$ reductase and to allopregnanolone (ALLO) by $3 \alpha$-hydroxysteroid dehydrogenase ( $3 \alpha-\mathrm{HSD}$ ) and is also the precursor for androgens, which are converted into estrogens by the enzyme aromatase.

This article is protected by copyright. All rights reserved. 
The neurosteroids influence growth and survival of nerve cells during development and are involved in the regulation of various brain and peripheral nerve functions, including behavioral, neuroendocrine and metabolic processes in adults ${ }^{17}$. Therefore, altered levels of neurosteroids during development or in adults is associated with neurodevelopmental, psychiatric or behavioral disorders. In this sense, an emerging therapeutic role of steroids such as sulphated pregnanes, ALLO or other pharmacological strategies that enhance neurosteroidogenesis is actually considered to improve both emotional and cognitive behavior in neuropsychiatric disorders ${ }^{18}$.

Developmental myelination is also influenced by neurosteroids. ALLO is present in high concentrations in late gestation. Preterm birth results in the delivery of neonates with reduced myelination in the cerebellum and immaturity of the oligodendrocyte lineage ${ }^{19}$. In turn, progesterone and its reduced metabolite ALLO stimulates myelination in organotypic cultures of rat cerebellum ${ }^{20}$. Moreover, oligodendrocytes and their precursors differentially express enzymes needed for progesterone and its metabolites synthesis suggesting a role for these compounds in oligodendrocytes proliferation and differentiation during development ${ }^{21}$. Androgens also show-a promyelinating role since higher levels of male hormones associate with increased expression of myelin proteins and oligodendrocyte density in the developing corpus callosum ${ }^{22}$.

Literature evidence indicates that changes of neurosteroids may be involved in the pathophysiology of MS. Thus, the brain of MS patients and EAE animals displays reduced ALLO and dehydroepiandrosterone (DHEA) levels and diminished expression of their synthesizing enzymes. Other studies have reported that progesterone and its reduced metabolites DHP and ALLO are altered in CSF and plasma of EAE rats and MS patients ${ }^{23,24}$. Interestingly, in EAE models, reduced levels of neurosteroids are frequently associated with inflammation and myelin loss ${ }^{25,26}$, while exogenous administration of progesterone or synthetic progestins prevents demyelination, enhances myelin repair and reduces CNS inflammation ${ }^{10,27,28}$. Furthermore, progesterone and the synthetic progestin Nestorone repair demyelinating lesions and increase oligodendrogenesis in the cuprizone model of $\mathrm{MS}^{29}$.

Previous work in the EAE model has shown that progesterone treatment restores normal neurosteroidogenesis and decreases neuropathology at the spinal cord level ${ }^{10,27,30}$. In view of these reports, the present study assessed if changes of neurosteroidogenesis also occurred in mice subjected to CPZ-induced demyelination. Cuprizone-treated animals are characterized by initial oligodendrocyte death, demyelination of neocortex, corpus callosum and hippocampus, together with recruitment of microglia/macrophages, astrocytes and oligodendrocyte progenitor cells (OPCs) ${ }^{31}$. When cuprizone diet is suspended and replaced with normal mice chow, oligodendrocytes are

This article is protected by copyright. All rights reserved. 
replenished and axons become remyelinated ${ }^{32}$. To analyze events at these different periods, we compared the expression of neurosteroidogenic proteins and enzymes and the glial reaction after cuprizone-induced demyelination and during the remyelination stage. We found that neurosteroidogenesis/myelination status and micro/astroglial reactivity are inversely related in the hippocampus and neocortex, suggesting an association of enhanced neurosteroidogenesis with remyelination.

\section{MATERIALS AND METHODS}

\subsection{Experimental animals and cuprizone treatment}

C57BL/6 female mice were bred and maintained in groups of five animals per cage under standard light conditions (12 light/dark cycles) at the facilities of the Department of Biological Chemistry, School of Pharmacy and Biochemistry of the University of Buenos Aires. Food and drinking water were given ad libitum. To induce demyelination, 8 weeks old mice were fed a standard powdered rodent chow mixed with $0.2 \%$ cuprizone (w/w) (bis-cyclohexanoneoxaldihydrazone, Sigma) during 35 days (CPZ D). Spontaneous remyelination occurred when animals were returned to normal diet for 14 further days (CPZ R). Mice were used at day 35 (CPZ D) and 14 days later (CPZ R). Age matched control mice received standard powdered chow without cuprizone (CTRL). All procedures were conducted in accordance with the recommendations set forth by the National Institute of Health Guide for Care and Use of Laboratory Animals (Publication No. 85-23, revised 1985) and CICUAL (Institutional Committee for the Care and Use of Laboratory Animals, University of Buenos Aires, Argentina). All efforts were made to minimize the number of animals for the different experiments.

\subsection{Real time $P C R$}

For real time PCR, mice were deeply anesthetized with a mixture of xylazine $(6 \mathrm{mg} / \mathrm{kg}$ i.p) and ketamine $(75 \mathrm{mg} / \mathrm{kg}$ i.p) and killed by decapitation. Total RNA was isolated from corpus callosum, hippocampus and cortex using Trizol reagent (Life Technologies, Invitrogen). All samples were precipitated with ethanol and then dissolved in distilled water at a concentration of $1 \mu \mathrm{g} / \mu \mathrm{L}$. Total RNA was subjected to Dnase 1 treatment (Promega) to remove residual contaminating genomic DNA. The concentration and purity of total RNA was determined by measuring the optical density at 260 and $280 \mathrm{~nm}$. cDNA templates for PCR amplification were synthesized from $1 \mu \mathrm{g}$ of total RNA

This article is protected by copyright. All rights reserved. 
using a MMLV High Performance reverse transcriptase kit (Epicentre, USA) for $60 \mathrm{~min}$ at $37^{\circ} \mathrm{C}$ in the presence of random hexamer primers. Table 1 shows the sequence of the forward and reverse primers employed for cyclophilin B, MBP, TNF $\alpha$, CD11b, StAR,TSPO, VDAC, P450scc, 3 $\beta$-HSD and $5 \alpha-$ reductase type I as already published ${ }^{30}$.Cyclofilin $B$ was used as a housekeeping gene based on the similarity of mRNA expression across all sample templates. Specificity of PCR amplification and the absence of dimers were confirmed by melting curve analysis. For amplification, 20-40 ng of cDNA was used and qPCR was performed under optimized conditions: $95{ }^{\circ} \mathrm{C}$ at $10 \mathrm{~min}$ followed by 40 cycles at $95^{\circ} \mathrm{C}$ for $0.15 \mathrm{~s}$ and $60^{\circ} \mathrm{C}$ for $1 \mathrm{~min}$. Primer concentrations varied between 0.2 and $0.4 \mu \mathrm{M}$. The relative gene expression for different mRNAs was determined using Syber Green (Roche) with a Step One Plus System (Applied Biosystems, Foster City, CA) and data were calculated using the $2^{-}$ ${ }^{\Delta \Delta c t}$ method ${ }^{28}$. Results were determined as fold induction compared to controls. At least two replicates were analyzed per target gene for each sample. Values are expressed as mean fold-change \pm SEM, and the level of significance was set at $p<0.05$. Five animals were used per experimental group for qPCR, composed of controls (CTRL), demyelinated (CPZD) and remyelinated (CPZ R) mice.

\subsection{Histology and Immunohistochemistry}

Animals were deeply anesthetized with a mixture of xylazine $(6 \mathrm{mg} / \mathrm{kg}$ i.p) and ketamine $(75 \mathrm{mg} / \mathrm{kg}$ i.p) and perfused intracardially with $25 \mathrm{ml}$ of $0.9 \% \mathrm{NaCl}$ solution followed by $25 \mathrm{ml} 4 \%$ paraformaldehyde (PFA) in $0.1 \mathrm{M}$ sodium phosphate buffer (PBS) pH 7. Brains were removed, fixed in the same fixative for $2 \mathrm{~h}\left(4^{\circ} \mathrm{C}\right)$, cryoprotected with a solution made of ethylene glycol-glycerol-0.1 M sodium phosphate buffer pH 7.4 (0.6:0.5:1.0) overnight. After a change of the same solution, brains were kept frozen at $-20{ }^{\circ} \mathrm{C}$ until used. Free floating sections of $60 \mu \mathrm{m}$ were obtained with a vibrotome (Pelco easislicer, Ted Pella) prepared for histological techniques. For immunohistochemistry, sections were exposed to methanol: $\mathrm{H}_{2} \mathrm{O}_{2}$ (50:50) for $30 \mathrm{~min}$ at room temperature (RT) $25{ }^{\circ} \mathrm{C}$, washed and blocked for $30 \mathrm{~min}$ in PBS containing $10 \%$ serum at $37{ }^{\circ} \mathrm{C}$. Sections were incubated overnight with the following antibodies: monoclonal anti-MBP (1:500, \#398212, Santa Cruz Labs), anti GFAP raised in goat (1:250, \#G3893, Sigma). An anti-StAR antibody raised in rabbit (gift from Dr. D. Stocco, Texas Tech University, Lubbock, TX 79430, USA) was also used after blocking with $3 \%$ albumin. After overnight incubation at $4^{\circ} \mathrm{C}$, sections were washed and exposed to the appropriate biotinylated anti mouse or antirabbit (1:200, Sigma) conjugated secondary antibody for 1 hour at RT. After a further washing step, the slides were incubated with Avidin/HRP-Biotin complex solution (Vectastain ABC Kit, Vector Laboratories, CA, USA) dilute 1:100 for one hour at RT. Immunoreactive cells were visualized by $3,3^{\prime}$ diaminobenzidine-tetra-

This article is protected by copyright. All rights reserved. 
hydrochloride $0.25 \mathrm{mg} / \mathrm{ml}$ working solution (Diaminobenzidine, Sigma) and $0.05 \% \mathrm{H}_{2} \mathrm{O}_{2}$ at RT for six minutes after the formation of avidin-biotin-complexes. The tissue was finally dried, dehydrated and mounted with Permount (Fischer Scientific, Pittsburgh, PA, USA). Fluorescence immunohistochemistry for microglia was performed by using an anti-ionizing calcium -binding adapter molecule 1 (IBA 1) antibody raised in rabbit (1:1500, \#019-19741,Wako, Japan) followed by an antirabbit secondary antibody conjugated with Alexa Fluor 488 (1:1000, Molecular Probes). Confocal studies for colocalization of StAR with CC1, GFAP and NeuN to label neurons were performed by using the previously mentioned primary antibodies for StAR, GFAP and monoclonal anti CC1 (1:100, \#OP80, Calbiochem) and mouse anti NeuN (1:100, MAB377, Millipore) followed by an antimouse secondary antibody conjugated with Alexa Fluor 555 or antirabbit conjugated with Alexa Fluor 488 (1:1000, Molecular Probes). After washes in PBS, sections were dried at room temperature and coverslipped with Fluoromont-G (Southern Biotech, USA). Specificity was evaluated by incubating the sections without primary antibody. To determine corpus callosum demyelination, we employed Sudan Black histochemistry. After a wash in alcohol $70 \%$ for 5 minutes, slides were immersed in Sudan Black 0.5\% solution for 30 minutes. After washes with water and alcohol 70\%, sections were mounted with PBS-Glycerol 1:1 ${ }^{33}$.

\subsection{Microscopy and quantitative analysis}

We analyzed every 8th section spanning the rostrocaudal extension of the hippocampus corresponding to Plates 41-51 from the stereotaxic atlas of the mouse brain ${ }^{34}$. DAB and fluorescent stained sections were examined and the region of interest was photographed using an Olympus BHS optic microscope equipped with a VT-C330N video camera or an Olympus DSU confocal microscopy (Tokio, Japan) equipped with the Cell Sense Dimension software, respectively. Digital images of corpus callosum, cortex and hippocampus were captured, taking care that every set of images were captured under the same light intensity and exposure time. Images were analyzed using the Optimas Program (Bioscan Optimas, USA) or the ImageJ Software, downloaded from the NIH website. MBP and Sudan Black staining was calculated by the inverse log of gray intensity per area (ILIGV/area). The number of astrocytes and microglial cells was calculated by counting GFAP and IBA1 positive cells per $\mathrm{mm}^{2}$. StAR protein expression was calculated in Cornu ammonis (CA) 3 region of the hippocampus as immunoreactive (IR) area after setting a fix threshold. Four/five animals were included in each group.

This article is protected by copyright. All rights reserved. 


\subsection{Statistical Analysis}

Group comparisons were carried out using ANOVA followed by Newman Keuls post hoc test. Differences were considered significant at the $p<0.05$ level. Statistics were performed using Prism 4 (GraphPad Prism Software Inc., La Jolla, CA).

\section{RESULTS}

As already mentioned, cuprizone treatment produces demyelination of different brain areas, whereas spontaneous remyelination develops after removal of the toxic insult 35. Therefore, we studied changes of neurosteroidogenic proteins and enzymes during demyelination and remyelination in three different brain areas: hippocampus, corpus callosum and cortex. The response of astrocytes, microglia and TNFa was also determined due to their crucial role in the pathology produced by cuprizone administration ${ }^{36}$

\subsection{Hippocampal myelin, glial reaction and neurosteroidogenesis in CPZ D and CPZ R mice.}

Feeding cuprizone for 5 weeks significantly reduced MBP mRNA and immunoreactive protein in hippocampus. The ANOVA revealed groups differences $\left(F_{(2,10)}=15.40 ; p<0.001\right.$ and $F_{(2,8)}=24.05$; $p<0.001$ respectively).Thus, MBP mRNA was reduced by $66 \%$ in CPZ D compared to control animals $(p<0.05)$ (Fig. 1A) whereas densitometric measurements of immunoreactive intensity per area demonstrated weaker MBP signal in CPZ D mice (Fig. 1B) ( $p<0.05$ vs. CTRL). Replacing the chelator by regular food for 14 days, increased MBP mRNA and MBP protein vs. CPZ D ( $p<0.001$ for both measurements) (Fig $1 \mathrm{~A}$ and $\mathrm{B}$ ). In addition, spontaneous remyelination increased MBP mRNA levels and immunoreactivity of CPZ R animals to a higher level than controls ( $p<0.05$ vs. CTRL for both measurements). Light microscopy images (Fig. 1C) shows the depletion of MBP in hippocampus of CPZ D (center image) compared to CTLR and CPZ R mice (left and right images, respectively).

Demyelination of cuprizone-fed mice was accompanied by a strong microgliosis of the whole hippocampus in the CPZ D group, as shown by quantitative analysis of a transcript and a histochemical marker in the stratum radiatum (Fig.1D and E). Statistical analysis by ANOVA showed significantly differences for CD11b mRNA $\left(F_{(2,8)}=10.82 ; p<0.001\right)$ and IBA1+ cells $\left(F_{(2,9)}=21.96\right.$; $\mathrm{p}<0.001)$. Thus, increased expression of the microglia marker CD11b mRNA and higher number of IBA1+ cells were found in the hippocampus of CPZ D mice compared to CTLR groups ( $p<0.01$ and

This article is protected by copyright. All rights reserved. 
p $<0.001$ respectively (Fig.1D and E). Conversely, both parameters were reduced during remyelination (CPZ R vs. CPZ D mice: $p<0.05$ for CD11b mRNA and $p<0.01$ for IBA1+ cells) (Fig.1D and E). Fig. F shows higher number of microglial cells in the CPZ D group (center image) compared to CTLR and CPZ R mice (left and right images, respectively). In this experiment, the number of GFAP+ astrocytes showed significant group differences in the ANOVA test $\left(F_{(2,9)}=22.55 ; p<0.001\right)$ and was markedly increased in the stratum lacunosum moleculare of the hippocampus of CPZ D vs. CTRL mice $(p<0.001)$ (Fig. 1G). This glial response was linked to inflammation, as shown by a significant changes in TNF $\alpha\left(F_{(2,8)}=35.08 p<0.0001\right)$, a main proinflammatory cytokine of activated astrocytes and microglia ${ }^{28}$. Thus, in parallel to reactive gliosis, TNF $\alpha$ mRNA showed a three-fold induction in CPZ D $(p<0.001)$ and a reduction in CPZ R mice ( $p<0.01$ vs. CPZ D) (Fig.1H)

After demonstrating the effectiveness of our protocol to produce demyelination and remyelination and changes of glial cells during these two periods, we studied neurosteroidogenesis by first measuring molecules belonging to the transduceosome complex. Fig. 2 shows the expression of StAR mRNA (Fig. 2A) and protein at the CA3 hippocampal level (B) in CTRL, CPZ D, and CPZ R mice. Quantitative data revealed significant group differences for STAR mRNA $\left(F_{(2,10)}=p<0.001\right)$ and protein $\left(F_{(2,9)}=4.99 ; p<0.05\right)$ by ANOVA. StAR mRNA and the corresponding protein immunoreactive area (IR Area) were reduced by $30 \%(p<0.01)$ and by $50 \%(p<0.05)$ respectively, compared to CTRL. Subsequent remyelination restored these parameters, as CPZ R was not different from CTRL levels (Fig. 2A and B). Fig.2C shows low signal for immunoreactive StAR in the CA3 hippocampus region (CPZ D) compared to the same region of CTRL and CPZ R mice. The transduceosome molecules VDAC and TSPO were also evaluated at the transcriptional level. Fig.2D shows no statistical difference in the levels of VDAC and TSPO during the demyelination and remyelination periods. However, TSPO showed a trend increase in CPZ D and a trend decrease in CPZ R. These changes may be due to changes of microglia, since TSPO is a recognized marker of these cells. The mRNAs for P450scc and $5 \alpha$-reductase showed significantly inter group differences $\left(F_{(2,10)}=6.31, p<0.05\right.$ and $F_{(2,10)}=16.36$, $p<0.001$ respectively). Both mRNAs were down-regulated by $30 \%$ during demyelination of CPZ D mice (Fig. 2D) ( $p<0.05$ and $p<0.001$ respectively vs. CTRL) and were recovered to control levels in CPZ $R$ mice ( $p$ : NS vs. CTRL). $3 \beta$-HSD mRNA showed a large intragroup variation, particularly in the remyelinated group, but without statistical significance.

These results suggest that in the hippocampus, cuprizone treatment produced demyelination, induced a proinflammatory status (IBA 1, GFAP, TNF $\alpha$ ) and down regulated some neurosteroidogenic parameters (StAR, P450scc, aromatase). Spontaneous remyelination following removal of cuprizone, instead, recovered myelin formation, decreased the glial reaction and neuroinflammation, and up-regulated neurosteroidogenesis.

This article is protected by copyright. All rights reserved. 


\subsection{Cortical myelin, glial reaction and neurosteroidogenesis in CPZ D and CPZ R mice.}

Cuprizone treatment targets myelin of several brain regions ${ }^{37,}{ }^{38}$. Therefore, we also determined the effectiveness of our cuprizone feeding protocol to influence myelin, glial cells and neurosteroidogenesis in the cerebral cortex. ANOVA results evidenced significant changes for MBP mRNA $\left(F_{(2,9)}=21.65 ; p<0.001\right)$ and for MBP protein $\left(F_{(2,8)}=20.19 ; p<0.001\right)$. Fig.3 shows that MBP transcripts (CPZ D, Fig. 3A1) and protein immunoreactivity (CPZ D, Fig. 3A2) were abruptly reduced in this area compared to CTRL ( $p<0.01$ and $p<0.001$ respectively). On remyelination day $14, M B P$ mRNA (CPZ R, Fig.3A1) and protein (Fig.3A2) significantly increased $(p<0.001$ and $p<0.01$ respectively vs. CPZ D) and were restored to CTRL levels in the case of MBP mRNA. The immunohistochemistry of Fig.3A shows a representative image of the demyelinated cortex of a CPZ D mouse, compared to the CTRL (left hand image) and the CPZ R mouse (right hand image).

We also observed activation of glial cells in the cortex area following cuprizone intoxication. (ANOVA for IBA1 $F_{(2,9)}=13.72 ; p<0.001$, GFAP $F_{(2,9)}=56.29 ; p<0.0001$ ) (Fig. 3B1- B3). Thus, the number of IBA1+ microglial cells (Fig.3B1) and GFAP+ cells per area (Fig.3B2) were duplicated in CPZ D mice compared to CTRL -reductase: levels ( $p<0.01$ and $p<0.001$, respectively). Simultaneously with glial reactivity, the levels of the proinflammatory cytokine TNF $\alpha$ (Fig.3B3) was also elevated in the demyelinated group ( $p<0.01$ vs. CTR). Conversely, on remyelination day 14, microglia (Fig.3B1), astrocyte reaction (Fig.3B2) as well as the proinflammatory mediator TNF $\alpha$ (Fig. 3B3) were significantly reduced vs. CPZ D ( $p<0.05$ for IBA1; $p<0.001$ for GFAP; $p<0.01$ for TNF $\alpha$ ). Thus, spontaneous remyelination returned abnormalities of glial cells and an inflammatory marker to levels of CTRL mice.

To evaluate neurosteroidogenesis in the cerebral cortex, we determined the transcripts of StAR, P450scc and $5 \alpha$-reductase. We concentrated in these molecules because they showed opposite modulation in the hippocampus of CPZ D and CPZ R mice, as shown in Fig.1. The three parameters disclosed significant differences by ANOVA (StAR: $F_{(2,14)}=7.79, p<0.01 ;$ P450scc: $F_{(2,11)}=7,33, p<0.01 ; 5 \alpha$-reductase: $\left.F_{(2,13)}=5.31, p<0.05\right)$. In agreement with findings in the hippocampus, the mRNAs for StAR (Fig.3C1), P450 scc (Fig.3C2) and $5 \alpha$-reductase (Fig.3C3) were down-regulated in the cortex during cuprizone-induced demyelination ( $p<0.05$ vs. CTRL for the three transcripts). In contrast, increased mRNAs for StAR ( $<<0.05$ ), P450 scc and $5 \alpha$-reductase ( $p<0.01$ for both) were found in remyelinated CPZ R mouse vs. CPZ D mice, reaching levels similar to those of CTRL mice. In the cerebral cortex, therefore, cuprizone demyelination was accompanied by astrogliosis, microgliosis, inflammation and decreased neurosteroidogenesis, whereas spontaneous remyelination normalized myelin expression, attenuated gliosis and inflammation, and increased neurosteroidogenesis.

This article is protected by copyright. All rights reserved. 


\subsection{Corpus callosum myelin, glial reaction and neurosteroidogenesis in CPZ D and CPZ R mice.}

Five weeks of cuprizone diet induced a marked demyelination of the corpus callosum, as shown by the decreased MBP mRNA and myelin histochemistry in CPZ D compared to CTRL mice $(p<0.05$ and $p<0.01$ respectively, Fig.4A1 and A2). Additionally, the density of IBA1+ cells increased 6 -fold in the CPZ D ( $p<0.001)$ (Fig.4B1) and the number of GFAP+ cells increased by 3 -fold $(p<0.001)$ vs. CTRL (Fig.4B2). After cuprizone withdrawal, MBP mRNA (Fig 4A1) and Sudan Black staining (Fig.4A2) was restored to CTRL levels ( $p<0.01$ vs. CPZ $D$, NS vs. CTRL and $p<0.001$ vs. CPZ $D, N S$ vs. CTRL; respectively). In the remyelinated corpus callosum of CPZ R mice, the number of astrocytes and microglia was reduced and the morphology of glial cells changed to a less reactive phenotype. The ANOVA test revealed significant group differences for IBA1+ cells $\left(F_{(2,9)}=41.32, p<0.0001\right)$ and GFAP+cells $\left(F_{(2,9)}=60.86, p<0.0001\right)$. Post-hoc comparisons showed significant changes for IBA1+ cells (CPZ D vs. CPZ R: $p<0.001$ ) and for GFAP + cells (CPZ D vs. CPZ R, p<0.05) (Fig.4B1 and B2). ANOVA results showed significant group differences for $\operatorname{TNF} \alpha\left(\mathrm{F}_{(2,8)}=12.29, \mathrm{p}<0.01\right)$; however, TNF $\alpha \mathrm{mRNA}$, an index of tissue inflammation, was increased to the same extent in CPZ D and CPZ R ( $p<0.001$ in both cases vs. CTRL (Fig.4B3)

Immunofluorescence images of IBA1 taken from the corpus callosum of CPZ D mice (Fig 4B4, central image), showed enhanced microglia activation compared with the neocortex and hippocampus. This microglia showed a globoid activated-phenotype and disposed "in chains" along the analyzed area. A notorious pathological response was also found for CPZ D astrocytes, which showed a hyperreactive phenotype bearing several GFAP+ processes (photograph not shown).

In analogy with hippocampus and cortex, neurosteroidogenic molecules of corpus callosum showed a decreased expression of StAR, P450scc and 5 $\alpha$-reductase mRNA after cuprizone feeding. (ANOVA: $\quad F_{(2,10)}=5.96, p<0.5 ; \quad F_{(2,10)}=15.28, p<0.001 ; \quad F_{(2,9)}=6.11, p<0.5$, respectively). Post hoc comparisons showed significant differences for StAR $(p<0.05), 5 \alpha$-reductase $(p<0.05)$ and P450scc $(p<0.001)$ vs. CTRL (Fig.4C1-3). However, when animals switched from cuprizone to normal diet, the expression of these transcripts remain stable at low levels except for $5 \alpha$-reductase that was recovered to control measurement. Thus, remyelination and decreased glial reaction of the corpus callosum was not accompanied by enhanced expression of all neurosteroidogenic molecules.

Although microglial cell number decreased upon remyelination in the three analyzed areas (Fig.5 A-cortex, B-hippocampus and C-corpus callosum), corpus callosum microglial cells still showed an activated round phenotype with thick processes (Fig.5C) in contrast to arborized gray matter cells which contained thinner processes and showed a resting appearance (Fig.5 A and B). Thus,

This article is protected by copyright. All rights reserved. 
neuroinflammation of the corpus callosum due to persistent high levels of TNF $\alpha$ by activated glial cells may prevent full recovery of neurosteroidogenesis.

\subsection{Immunostaining for StAR and markers of neurons, oligodendrocytes and astrocytes.}

Studies were also performed to determine the localization of StAR protein in control and treated animals. An extensive neuronal localization was demonstrated for StAR in both groups in hippocampus, particularly in CA3 region as previously shown in Fig. $2 \mathrm{C}$. In addition, using NeuN staining we showed that STAR+ neurons were abundantly found in cerebral cortex (Fig.5F) while StAR immunoreaction in corpus callosum was scarce (not shown). GFAP labeling indicated that most of the reactive astrocytes found in demyelinated animals colocalized with StAR in cortex. Similar images were found for hippocampus and corpus callosum. Fig.5I shows the presence of GFAP/StAR double positive cells in cortex (arrows). Instead, colocalization with CC1 marker showed that the majority of oligodendrocytes were devoid of StAR protein in both groups in the three analyzed areas Fig.5L shows the absence of StAR immunostaining in a CC1 cell (arrow) in the cortex of a cuprizonetreated animal.

\section{DISCUSSION}

Cuprizone treatment is useful to study factors involved in demyelination and remyelination, resembling the relapsing-remitting form of $\mathrm{MS}^{39}$. Our results in mice subjected to cuprizone-induced demyelination revealed that the expression of neurosteroidogenic proteins and enzymes decreased in parallel with myelin loss and glial proliferation and reactivity. These parameters were restored during spontaneous remyelination, suggesting that remyelination and neurosteroidogenesis may be interconnected events at least in gray matter regions such as hippocampus and cerebral cortex.

In the present study, the loss of myelin induced by cuprizone in the hippocampus, neocortex and corpus callosum was concomitant to the reduced expression of the mRNA of StAR and P450scc, suggesting impairment of the initial mitochondrial steps required for steroid synthesis. Interestingly, CPZ treatment to Swiss mice also showed lower levels of brain cholesterol among other myelin lipids ${ }^{40}$. Diminished expression of StAR and probably cholesterol prevents cholesterol transport, accession to the side chain-cleavage enzyme P450scc and conversion into pregnenolone. Furthermore, the microsomal enzyme $5 \alpha$-reductase that reduces progesterone to dihydroprogesterone (DHP) was also down-regulated in the demyelinated regions. These results suggest that pregnenolone, and possibly progesterone, progesterone reduced derivatives, androgens and estrogens may be diminished in

This article is protected by copyright. All rights reserved. 
cuprizone-induced demyelination. Therefore, the induction of steroidogenic enzymes and proteins coincide with myelin formation and attenuation of the glial reaction observed during the remyelination stage.

Regarding the mechanism involved in the abnormal steroidogenesis of cuprizone-treated mice, reports indicate that steroidogenic genes and proteins, such as StAR and P450 enzymes, are damaged by products released from reactive microglia and astrocytes ${ }^{41,42}$. In normal conditions, StAR is found in mitochondria from neurons and astrocytes ${ }^{43}, 44$, VDAC is found predominantly in neuronal mitochondria ${ }^{14,45,46}$, whereas P450scc is a mitochondrial-based enzyme found in neurons, astrocytes and oligodendrocytes ${ }^{46,47}$. Astrocytes are a major site for expression of $3 \beta-H S D$ highlighting a key role of this cells type in all basic steroidogenic pathways ${ }^{48}$. Five $\alpha$-reductase type 1 is abundantly expressed in the brain and is mainly localized in glial cells, such as astrocytes and oligodendrocytes ${ }^{49}$.

The production of steroids and the mechanisms regulating its synthesis might vary in different glial cells and neurons depending on different needs in health and disease. Also the steroidogenic activity of neurons and glia seems to be complementary. In vitro, the $5 \alpha$-reductase activity and the $3 \alpha-\mathrm{HSD}$ activity present in astrocytes are stimulated by the simultaneous presence of neurons ${ }^{50}$ indicating a communication between the two populations of cells in the metabolism of steroid hormones. Moreover, estradiol, which can be produced by neurons, stimulates progesterone synthesis in astrocytes and control cellular levels of neurosteroid precursors such as DHEA and pregnenolone 51,52 . Therefore, down-regulation of StAR, P40scc and $5 \alpha$-reductase in the hippocampus, neocortex and corpus callosum of CPZ D animals represents abnormalities of neurons and several glial cell types. Double-labeling of StAR with specific cell markers have shown intense colocalization with neurons and astrocytes, weak colocalization with a marker of mature oligodendrocytes, suggesting involvement of these cells types in changes of neurosteroidogenesis of CPZ D and CPZ R mice.

An important question remains for the present investigation, i.e., the mechanisms producing changes in neurosteroidogenesis. It is possible that the recovery in the expression of the enzymes after the toxic removal, is related to lower levels of neuroinflammatory mediators considering that inflammatory molecules like TNF $\alpha$ has been associated with mitochondrial dysfunction and ROS production ${ }^{53}$. Additionally, mitochondrial dysfunction also contributes to the loss of the homeostatic mechanism of cholesterol trafficking which has a central role in the microglial- astrocyte-neuron circuitry and steroid hormone synthesis ${ }^{54}$. Thus, in this context, OPC may proliferate and differentiate into mature oligodendrocytes capable of further synthesis of neurosteroids, in addition

This article is protected by copyright. All rights reserved. 
to astrocytes and neurons. Literature reports indicate a multifactorial regulation of this pathway as well. Responsible factors include the NMDA receptor, calcium influx, the pregnane-X-receptor (PXR), TSPO ligands and the intracellular progesterone receptor membrane component 1 (PGRCM1) ${ }^{55-57}$. Liver $X$ receptor (LXR) may be also implicated, because its activation leads to increased neuroprogesterone synthesis, stimulation of oligodendrocytes maturation and remyelination ${ }^{58}$. Neurosteroidogenesis is also modulated by the prevailing environmental conditions, such as peripheral nerve lesion, transient middle cerebral artery occlusion, spinal cord injury, diabetes, the presence of micro RNAs and EAE ${ }^{25,28,59}$. Further complexity is added by ontogenetic studies, which show that enzymes of the neurosteroidogenic pathway are either increased (P450scc, StAR) or decreased (3ß-HSD) ${ }^{60,61}$ during development. Changes closer to the cuprizone model occur during peripheral nerve lesion. In this case, the key enzyme of progesterone synthesis 3 $\beta$-HSD shows changes in parallel with the regulation of peripheral myelin proteins, supporting our hypothesis for a role of locally synthesized neurosteroids in myelination ${ }^{62}$. In summary, whether single or multiple mechanisms are set in motion for the induction of neurosteroidogenesis and myelin repair in the cuprizone model remains to be elucidated by future experiments.

Our data showed that the extent of glial reaction was inversely related with myelin status and neurosteroidogenesis. For example, microglial cells identified by IBA1 immunoreaction and CD11b mRNA, as well as GFAP+ astrocytes were increased in number and adopted a reactive phenotype in CPZ D mice. These activated cells elicited an inflammatory response, as shown by the up-regulation of the inflammatory gene TNF $\alpha^{28}$. TNF $\alpha$ released from reactive microglia and reactive astrocytes causes toxicity to neurons ${ }^{63,64}$, increases oligodendrocyte apoptosis ${ }^{65}$ and decreases proliferation, and maturation of oligodendroglial precursor cells (OPCS) ${ }^{66}$. In the cuprizone model, TNF $\alpha$ binding to its receptor TNFR1 is linked to demyelination ${ }^{67}$, whereas in the EAE model, TNF $\alpha$ binding TNFR1 located in astrocytes impairs synaptic connections and learning and memory in the hippocampus ${ }^{68}$. Cuprizone treatment also produces a prominent demyelination and perturbations of the hippocampal circuitry ${ }^{69}$, in addition to demyelination of the forebrain cortex and the corpus callosum ${ }^{70}$. These abnormalities may be responsible for less social interaction, decreased special working memory and seazures described in cuprizone treated mice ${ }^{71,72}$. Endogenous neurosteroids regulate neuronal excitability by allosteric activation of synaptic and extrasynaptic $G_{A B A_{A}}$ receptors and ALLO have been shown to have anticonvulsant properties, to modulate social performance and prevent memory impairment ${ }^{73,74}$. Therefore, altered neurosteroidogenesis in addition to other factors including compromised white matter and neurotransmitters system may contribute to these behavior deficits.

This article is protected by copyright. All rights reserved. 
Notably, the hippocampus and cortex showed a strong but time limited inflammatory response upon demyelination. After fourteen days of cuprizone removal, the density of glial cells and inflammatory stimulus were restored to control levels. At this time, the mRNAs of steroidogenic proteins were also increased suggesting enhanced function of mitochondria and endoplasmic reticulum. Interestingly, MBP protein and mRNA was also recovered in the hippocampus and neocortex, suggesting possible myelin-protective effects of endogenous steroids. Literature reports have conclusively demonstrated the promyelinating, neuroprotective and antiinflammatory effects of sex steroids in the CNS ${ }^{75,76}$. In cuprizone demyelination, the combined treatment with progesterone and estradiol of young mice counteracts the myelin loss ${ }^{77}$, whereas single progesterone treatment increases the number of mature oligodendrocytes, its precursors (OPCS) and myelin proteins ${ }^{78}$. Using EAE mice, we have previously published increased expression of neurosteroidogenic enzymes, improved clinical signs and myelin preservation after progesterone treatment ${ }^{30}$. Interestingly, mitochondrion is a target of progestin action. Pharmacological studies describe an increase in electron transport chain and decrease oxidative stress after exogenous administration of progesterone and estrogen ${ }^{79,80}$. Therefore, steroids may produce a "feed forward" mechanism stabilizing mitochondria and stimulating their own synthesis.

Based on supporting reports, the possibility exists that the principal source of steroids regulating myelin and glial cells in cuprizone demyelination and remyelination phases derive from neurosteroidogenesis. Literature data indicates that ovariectomization does not influence the extent of cuprizone demyelination ${ }^{29}$. Furthermore, cuprizone treatment disrupts estrous cyclicity from the first week of intake and reduces uterine weight suggesting a decreased level in circulating ovarian hormone levels. After the removal of the quelator, normalization of the estrous cycles may take more than three weeks ${ }^{81}$. Therefore, the recovery of steroidogenic enzymes and myelin after fifteen days may be independent on ovarian steroids.

Cuprizone toxicity elicits an inflammatory reaction revealed by reactive gliosis and upregulation of pro-inflammatory cytokines such us TNF $\alpha$. The latter is known to play an important role in oligodendrocyte death and demyelination ${ }^{67}$. Estrogens and progesterone has shown antiinflammatory actions by repressing DNA-binding activity of NF-KB and transcription of NF-KB targeted proinflammatory cytokines including TNF- $\alpha{ }^{82}$. Moreover, progesterone also switches microglial cells from a proinflammatory (M1) to an antiinflammatory (M2) phenotype in cuprizone demyelination ${ }^{83}$. Therefore, our data suggest that increased neurosteroidogenesis during remyelination may also attenuate inflammatory mediators in hippocampus and neocortex.

This article is protected by copyright. All rights reserved. 
Among the three areas analyzed, the microglial reaction, based on the number and morphology of the cells, was stronger in the demyelinated corpus callosum compared to the hippocampus or neocortex in consonance with published data ${ }^{70}$. Although microglial density was dampened after cuprizone removal in the three brain regions, activated phenotype and proinflammatory products such as TNF $\alpha$ remained elevated in corpus callosum. It is possible that the amount of myelin debris generated following demyelination in the myelin rich corpus callosum and the myelin sparse grey matter may drive microglial activation in different magnitudes considering the very active role of these cells in cuprizone-induced demyelination ${ }^{67}$. Therefore, it is feasible that normalization of inflammation requires longer times in the first region compared to hippocampus or cortex.

In the cortex of control animals the density and proliferation rate of OPCs is lower compared to the corpus callosum ${ }^{70}$. Here, the immunoreactivity for MBP and the amount of oligodendrocytes (not shown) upon cuprizone treatment and subsequent remyelination, followed the same dynamics in both grey and white matter structures despite obvious differences in myelination.

Although astrocyte proliferation was observed in the investigated brain region, it was more pronounced in white matter similar to microglia in coincidence with higher myelin debris during a demyelinating event. Interestingly, these results agree with the notion that astrocytes are responsible for recruitment of microglia and the latter removes myelin debris and promotes remyelination ${ }^{84}$.

In this scenario, callosal mitochondria and microsomal-based neurosteroidogenesis did not recover completely. The elevation in $5 \alpha$-reductase expression may be due to the increase number of oligodendrocytes. Since this enzyme exhibited a 5-fold higher activity in oligodendrocytes, its elevation in corpus callosum of CPZ R might lead to high levels of the 5 alpha-reduced derivatives from PROG or testosterone such as 5 alpha-dihydroprogesterone (5 alpha-DHPROG) and 5 alphadihydrotestosterone (5 alpha DHT) ${ }^{21}$.

In summary, we showed that during the remyelination period, increased neurosteroidogenesis plus reduced neuroneuroinflammation and glial reaction associate with enhanced myelin synthesis in the hippocampus and neocortex from cuprizone-treated mice. Validity of preclinical studies should be considered to explain events taking place in the relapsing-remitting form of MS patients.

This article is protected by copyright. All rights reserved. 


\section{ACKNOWLEDGEMENTS}

This work was supported by grants from the Ministry of Science and Technology (PICT 2012-0009), CONICET (PIP-112201201-00016), the University of Buenos Aires (Ubacyt 20020130100418 BA), Fundación Baron and Fundación Williams. These fundings sources had no role in the collection, analysis and interpretation of data; in the writing of the report; and in the decision to submit the article for publication.

The authors report no conflict of interest.

\section{REFERENCES}

1.Stadelmann C. Multiple sclerosis as a neurodegenerative disease: pathology, mechanisms and therapeutic implications. Current opinion in neurology 2011; 24: 224-9.

2.Dutta R, Trapp BD. Mechanisms of neuronal dysfunction and degeneration in multiple sclerosis. Progress in neurobiology 2011; 93: 1-12.

3.Trapp BD, Nave KA. Multiple sclerosis: an immune or neurodegenerative disorder? Annual review of neuroscience 2008 ; 31: 247-69.

4.Chao MJ, Ramagopalan SV, Herrera BM, Orton SM, Handunnetthi L, Lincoln MR, Dyment DA, Sadovnick AD, Ebers GC. MHC transmission: insights into gender bias in MS susceptibility. Neurology 2011; 76: 242-6.

5.Confavreux C, Hutchinson M, Hours MM, Cortinovis-Tourniaire P, Moreau T. Rate of pregnancyrelated relapse in multiple sclerosis. Pregnancy in Multiple Sclerosis Group. The New England journal of medicine 1998; 339: 285-91.

6.Giatti S, Rigolio R, Romano S, Mitro N, Viviani B, Cavaletti G, Caruso D, Garcia-Segura LM, Melcangi RC. Dihydrotestosterone as a Protective Agent in Chronic Experimental Autoimmune Encephalomyelitis. Neuroendocrinology 2015; 101: 296-308.

7.Benedek G, Zhang J, Bodhankar S, Nguyen H, Kent G, Jordan K, Manning D, Vandenbark AA, Offner $\mathrm{H}$. Estrogen induces multiple regulatory $B$ cell subtypes and promotes $M 2$ microglia and neuroprotection during experimental autoimmune encephalomyelitis. Journal of neuroimmunology 2016; 293: 45-53.

8.Ziehn MO, Avedisian AA, Dervin SM, Umeda EA, O'Dell TJ, Voskuhl RR. Therapeutic testosterone administration preserves excitatory synaptic transmission in the hippocampus during autoimmune demyelinating disease. The Journal of neuroscience : the official journal of the Society for Neuroscience 2012; 32: 12312-24.

9.Garay L, Deniselle MC, Meyer M, Costa JJ, Lima A, Roig P, De nicola AF. Protective effects of progesterone administration on axonal pathology in mice with experimental autoimmune encephalomyelitis. Brain research 2009; 1283: 177-85.

This article is protected by copyright. All rights reserved. 
10.Garay L, Gonzalez Deniselle MC, Lima A, Roig P, De Nicola AF. Effects of progesterone in the spinal cord of a mouse model of multiple sclerosis. The Journal of steroid biochemistry and molecular biology 2007; 107: 228-37.

11.Yates MA, Li Y, Chlebeck P, Proctor T, Vandenbark AA, Offner H. Progesterone treatment reduces disease severity and increases IL-10 in experimental autoimmune encephalomyelitis. Journal of neuroimmunology 2010; 220: 136-9.

12.Yu HJ, Fei J, Chen XS, Cai QY, Liu HL, Liu GD, Yao ZX. Progesterone attenuates neurological behavioral deficits of experimental autoimmune encephalomyelitis through remyelination with nucleus-sublocalized Olig1 protein. Neuroscience letters 2010; 476: 42-5.

13.Bebo BF, Jr., Fyfe-Johnson A, Adlard K, Beam AG, Vandenbark AA, Offner H. Low-dose estrogen therapy ameliorates experimental autoimmune encephalomyelitis in two different inbred mouse strains. J Immunol 2001; 166: 2080-9.

14.Mellon SH, Deschepper CF. Neurosteroid biosynthesis: genes for adrenal steroidogenic enzymes are expressed in the brain. Brain research 1993; 629: 283-92.

15.Plassart-Schiess E, Baulieu EE. Neurosteroids: recent findings. Brain research Brain research reviews 2001; 37: 133-40.

16.King SR, Manna PR, Ishii T, Syapin PJ, Ginsberg SD, Wilson K, Walsh LP, Parker KL, Stocco DM, Smith RG, Lamb DJ. An essential component in steroid synthesis, the steroidogenic acute regulatory protein, is expressed in discrete regions of the brain. The Journal of neuroscience : the official journal of the Society for Neuroscience 2002; 22: 10613-20.

17.Baulieu EE. [Neurosteroids, their role in brain physiology: neurotrophicity, memory, aging...]. Bulletin de I'Academie nationale de medecine 2001; 185: 349-69; discussion 70-2.

18. Locci A, Pinna G. Neurosteroid biosynthesis down-regulation and changes in GABAA receptor subunit composition: a biomarker axis in stress-induced cognitive and emotional impairment. British journal of pharmacology 2017; 174: 3226-41.

19.Kelleher MA, Palliser HK, Walker DW, Hirst JJ. Sex-dependent effect of a low neurosteroid environment and intrauterine growth restriction on foetal guinea pig brain development. The Journal of endocrinology 2011; 208: 301-9.

20.Ghoumari AM, Baulieu EE, Schumacher M. Progesterone increases oligodendroglial cell proliferation in rat cerebellar slice cultures. Neuroscience 2005; 135: 47-58.

21.Gago N, Akwa Y, Sananes N, Guennoun R, Baulieu EE, El-Etr M, Schumacher M. Progesterone and the oligodendroglial lineage: stage-dependent biosynthesis and metabolism. Glia 2001; 36: 295-308.

22.Abi Ghanem C, Degerny C, Hussain R, Liere P, Pianos A, Tourpin S, Habert R, Macklin WB, Schumacher $M$, Ghoumari AM. Long-lasting masculinizing effects of postnatal androgens on myelin governed by the brain androgen receptor. PLoS genetics 2017; 13: e1007049.

This article is protected by copyright. All rights reserved. 
23.Caruso D, Melis M, Fenu G, Giatti S, Romano S, Grimoldi M, Crippa D, Marrosu MG, Cavaletti G, Melcangi RC. Neuroactive steroid levels in plasma and cerebrospinal fluid of male multiple sclerosis patients. Journal of neurochemistry 2014; 130: 591-7.

24.Giatti S, D'Intino G, Maschi O, Pesaresi M, Garcia-Segura LM, Calza L, Caruso D, Melcangi RC. Acute experimental autoimmune encephalomyelitis induces sex dimorphic changes in neuroactive steroid levels. Neurochemistry international 2010; 56: 118-27.

25.Noorbakhsh F, Ellestad KK, Maingat F, Warren KG, Han MH, Steinman L, Baker GB, Power C. Impaired neurosteroid synthesis in multiple sclerosis. Brain : a journal of neurology 2011; 134: 270321.

26. Boghozian R, McKenzie BA, Saito LB, Mehta N, Branton WG, Lu J, Baker GB, Noorbakhsh F, Power C. Suppressed oligodendrocyte steroidogenesis in multiple sclerosis: Implications for regulation of neuroinflammation. Glia 2017; 65: 1590-606.

27.Garay L, Gonzalez Deniselle MC, Sitruk-Ware R, Guennoun R, Schumacher M, De Nicola AF. Efficacy of the selective progesterone receptor agonist Nestorone for chronic experimental autoimmune encephalomyelitis. Journal of neuroimmunology 2014; 276: 89-97.

28.Garay LI, Gonzalez Deniselle MC, Brocca ME, Lima A, Roig P, De Nicola AF. Progesterone downregulates spinal cord inflammatory mediators and increases myelination in experimental autoimmune encephalomyelitis. Neuroscience 2012; 226: 40-50.

29.El-Etr M, Rame M, Boucher C, Ghoumari AM, Kumar N, Liere P, Pianos A, Schumacher M, SitrukWare R. Progesterone and nestorone promote myelin regeneration in chronic demyelinating lesions of corpus callosum and cerebral cortex. Glia 2015; 63: 104-17.

30.Garay L, Gonzalez Giqueaux P, Guennoun R, Schumacher M, Gonzalez Deniselle MC, De Nicola AF. Progesterone treatment modulates mRNA OF neurosteroidogenic enzymes in a murine model of multiple sclerosis. The Journal of steroid biochemistry and molecular biology 2017; 165: 421-9.

31. Hiremath MM, Saito Y, Knapp GW, Ting JP, Suzuki K, Matsushima GK. Microglial/macrophage accumulation during cuprizone-induced demyelination in $\mathrm{C} 57 \mathrm{BL} / 6$ mice. Journal of neuroimmunology 1998; 92: 38-49.

32.Matsushima GK, Morell P. The neurotoxicant, cuprizone, as a model to study demyelination and remyelination in the central nervous system. Brain pathology 2001; 11: 107-16.

33.Ineichen BV, Weinmann O, Good N, Plattner PS, Wicki C, Rushing EJ, Linnebank M, Schwab ME. Sudan black: a fast, easy and non-toxic method to assess myelin repair in demyelinating diseases. Neuropathology and applied neurobiology 2017; 43: 242-51.

34.Paxinos. The rat nervous system (volume 2), 1985.

35.Franklin RJ, Kotter MR. The biology of CNS remyelination: the key to therapeutic advances. Journal of neurology 2008; 255 Suppl 1: 19-25.

This article is protected by copyright. All rights reserved. 
36.Voss EV, Skuljec J, Gudi V, Skripuletz T, Pul R, Trebst C, Stangel M. Characterisation of microglia during de- and remyelination: can they create a repair promoting environment? Neurobiology of disease 2012; 45: 519-28.

37.Groebe A, Clarner T, Baumgartner W, Dang J, Beyer C, Kipp M. Cuprizone treatment induces distinct demyelination, astrocytosis, and microglia cell invasion or proliferation in the mouse cerebellum. Cerebellum 2009; 8: 163-74.

38.Pott F, Gingele S, Clarner T, Dang J, Baumgartner W, Beyer C, Kipp M. Cuprizone effect on myelination, astrogliosis and microglia attraction in the mouse basal ganglia. Brain research 2009; 1305: 137-49.

39.van der Star BJ, Vogel DY, Kipp M, Puentes F, Baker D, Amor S. In vitro and in vivo models of multiple sclerosis. CNS \& neurological disorders drug targets 2012; 11: 570-88.

40. Millet V, Moiola CP, Pasquini JM, Soto EF, Pasquini LA. Partial inhibition of proteasome activity enhances remyelination after cuprizone-induced demyelination. Experimental neurology 2009; 217: 282-96.

41.Diemer T, Allen JA, Hales KH, Hales DB. Reactive oxygen disrupts mitochondria in MA-10 tumor Leydig cells and inhibits steroidogenic acute regulatory (StAR) protein and steroidogenesis. Endocrinology 2003; 144: 2882-91.

42.Georgiou M, Perkins LM, Payne AH. Steroid synthesis-dependent, oxygen-mediated damage of mitochondrial and microsomal cytochrome P-450 enzymes in rat Leydig cell cultures. Endocrinology 1987; 121: 1390-9.

43.King SR, Stocco DM. Steroidogenic acute regulatory protein expression in the central nervous system. Frontiers in endocrinology 2011; 2: 72.

44.Sierra A, Lavaque E, Perez-Martin M, Azcoitia I, Hales DB, Garcia-Segura LM. Steroidogenic acute regulatory protein in the rat brain: cellular distribution, developmental regulation and overexpression after injury. The European journal of neuroscience 2003; 18: 1458-67.

45.Papadopoulos V, Aghazadeh Y, Fan J, Campioli E, Zirkin B, Midzak A. Translocator proteinmediated pharmacology of cholesterol transport and steroidogenesis. Molecular and cellular endocrinology 2015; 408: 90-8.

46.Zwain IH, Yen SS. Neurosteroidogenesis in astrocytes, oligodendrocytes, and neurons of cerebral cortex of rat brain. Endocrinology 1999; 140: 3843-52.

47.Mellon SH, Griffin LD. Neurosteroids: biochemistry and clinical significance. Trends in endocrinology and metabolism: TEM 2002; 13: 35-43.

48.Emanuelsson I, Almokhtar M, Wikvall K, Gronbladh A, Nylander E, Svensson AL, Fex Svenningsen A, Norlin M. Expression and regulation of CYP17A1 and 3beta-hydroxysteroid dehydrogenase in cells of the nervous system: Potential effects of vitamin $D$ on brain steroidogenesis. Neurochemistry international 2018; 113: 46-55.

This article is protected by copyright. All rights reserved. 
49. Kiyokage E, Toida K, Suzuki-Yamamoto T, Ishimura K. Cellular localization of 5alpha-reductase in the rat cerebellum. Journal of chemical neuroanatomy 2014; 59-60: 8-16.

50.Melcangi RC, Celotti F, Martini L. Progesterone 5-alpha-reduction in neuronal and in different types of glial cell cultures: type 1 and 2 astrocytes and oligodendrocytes. Brain research 1994; 639: 202-6.

51.Sinchak K, Mills RH, Tao L, LaPolt P, Lu JK, Micevych P. Estrogen induces de novo progesterone synthesis in astrocytes. Developmental neuroscience 2003; 25: 343-8.

52. Wicher G, Norlin M. Estrogen-mediated regulation of steroid metabolism in rat glial cells; effects on neurosteroid levels via regulation of CYP7B1-mediated catalysis. The Journal of steroid biochemistry and molecular biology 2015; 145: 21-7.

53.Fischer R, Maier O. Interrelation of oxidative stress and inflammation in neurodegenerative disease: role of TNF. Oxidative medicine and cellular longevity 2015; 2015: 610813.

54.Graham A, Allen AM. Mitochondrial function and regulation of macrophage sterol metabolism and inflammatory responses. World journal of cardiology 2015; 7: 277-86.

55.Kimoto T, Tsurugizawa T, Ohta Y, Makino J, Tamura H, Hojo Y, Takata N, Kawato S. Neurosteroid synthesis by cytochrome p450-containing systems localized in the rat brain hippocampal neurons: $\mathrm{N}$ methyl-D-aspartate and calcium-dependent synthesis. Endocrinology 2001; 142: 3578-89.

56.Porcu P, Barron AM, Frye CA, Walf AA, Yang SY, He XY, Morrow AL, Panzica GC, Melcangi RC. Neurosteroidogenesis Today: Novel Targets for Neuroactive Steroid Synthesis and Action and Their Relevance for Translational Research. Journal of neuroendocrinology 2016; 28: 12351.

57. Wessel L, Olbrich L, Brand-Saberi B, Theiss C. New aspects of progesterone interactions with the actin cytoskeleton and neurosteroidogenesis in the cerebellum and the neuronal growth cone. The journal of histochemistry and cytochemistry : official journal of the Histochemistry Society 2014; 62: $835-45$

58.Meffre D, Shackleford G, Hichor M, Gorgievski V, Tzavara ET, Trousson A, Ghoumari AM, Deboux C, Nait Oumesmar B, Liere P, Schumacher M, Baulieu EE, Charbonnier F, Grenier J, Massaad C. Liver X receptors alpha and beta promote myelination and remyelination in the cerebellum. Proceedings of the National Academy of Sciences of the United States of America 2015; 112: 7587-92.

59.Labombarda F, Pianos A, Liere P, Eychenne B, Gonzalez S, Cambourg A, De Nicola AF, Schumacher $M$, Guennoun R. Injury elicited increase in spinal cord neurosteroid content analyzed by gas chromatography mass spectrometry. Endocrinology 2006; 147: 1847-59.

60.Compagnone NA, Bulfone A, Rubenstein JL, Mellon SH. Expression of the steroidogenic enzyme P450scc in the central and peripheral nervous systems during rodent embryogenesis. Endocrinology 1995; 136: 2689-96.

61.Romano S, Mitro N, Giatti S, Diviccaro S, Pesaresi M, Spezzano R, Audano M, Garcia-Segura LM, Caruso D, Melcangi RC. Diabetes induces mitochondrial dysfunction and alters cholesterol

This article is protected by copyright. All rights reserved. 
homeostasis and neurosteroidogenesis in the rat cerebral cortex. The Journal of steroid biochemistry and molecular biology 2018; 178: 108-16.

62.Robert F, Guennoun R, Desarnaud F, Do-Thi A, Benmessahel Y, Baulieu EE, Schumacher M. Synthesis of progesterone in Schwann cells: regulation by sensory neurons. The European journal of neuroscience 2001; 13: 916-24.

63.Neniskyte U, Vilalta A, Brown GC. Tumour necrosis factor alpha-induced neuronal loss is mediated by microglial phagocytosis. FEBS letters 2014; 588: 2952-6.

64.Sun L, Shen R, Agnihotri SK, Chen Y, Huang Z, Bueler H. Lack of PINK1 alters glia innate immune responses and enhances inflammation-induced, nitric oxide-mediated neuron death. Scientific reports 2018; 8: 383.

65.Gerstner B, Buhrer C, Rheinlander C, Polley O, Schuller A, Berns M, Obladen M, FelderhoffMueser U. Maturation-dependent oligodendrocyte apoptosis caused by hyperoxia. J Neurosci Res 2006; 84: 306-15.

66.Schmitz T, Ritter J, Mueller S, Felderhoff-Mueser U, Chew L, Gallo V. Cellular changes underlying hyperoxia-induced delay of white matter development. The Journal of neuroscience : the official journal of the Society for Neuroscience 2011; 31: 4327-44.

67.Pasquini LA, Calatayud CA, Bertone Una AL, Millet V, Pasquini JM, Soto EF. The neurotoxic effect of cuprizone on oligodendrocytes depends on the presence of pro-inflammatory cytokines secreted by microglia. Neurochemical research 2007; 32: 279-92.

68. Habbas S, Santello M, Becker D, Stubbe H, Zappia G, Liaudet N, Klaus FR, Kollias G, Fontana A, Pryce CR, Suter T, Volterra A. Neuroinflammatory TNFalpha Impairs Memory via Astrocyte Signaling. Cell 2015; 163: 1730-41.

69. Hubner NS, Mechling AE, Lee HL, Reisert M, Bienert T, Hennig J, von Elverfeldt D, Harsan LA. The connectomics of brain demyelination: Functional and structural patterns in the cuprizone mouse model. Neurolmage 2017; 146: 1-18.

70.Gudi V, Moharregh-Khiabani D, Skripuletz T, Koutsoudaki PN, Kotsiari A, Skuljec J, Trebst C, Stangel $M$. Regional differences between grey and white matter in cuprizone induced demyelination. Brain research 2009; 1283: 127-38.

71.Lapato AS, Szu JI, Hasselmann JPC, Khalaj AJ, Binder DK, Tiwari-Woodruff SK. Chronic demyelination-induced seizures. Neuroscience 2017; 346: 409-22.

72.Xu H, Yang HJ, Zhang Y, Clough R, Browning R, Li XM. Behavioral and neurobiological changes in C57BL/6 mice exposed to cuprizone. Behavioral neuroscience 2009; 123: 418-29.

73.Ebihara K, Fujiwara H, Awale S, Dibwe DF, Araki R, Yabe T, Matsumoto K. Decrease in endogenous brain allopregnanolone induces autism spectrum disorder (ASD)-like behavior in mice: A novel animal model of ASD. Behavioural brain research 2017; 334: 6-15.

This article is protected by copyright. All rights reserved. 
74.Escudero C, Casas S, Giuliani F, Bazzocchini V, Garcia S, Yunes R, Cabrera R. Allopregnanolone prevents memory impairment: effect on mRNA expression and enzymatic activity of hippocampal 3alpha hydroxysteroid oxide-reductase. Brain research bulletin 2012; 87: 280-5.

75.Khaksari M, Soltani Z, Shahrokhi N. Effects of Female Sex Steroids Administration on Pathophysiologic Mechanisms in Traumatic Brain Injury. Translational stroke research 2017.

76.Raghava N, Das BC, Ray SK. Neuroprotective effects of estrogen in CNS injuries: insights from animal models. Neuroscience and neuroeconomics 2017; 6: 15-29.

77.Acs P, Kipp M, Norkute A, Johann S, Clarner T, Braun A, Berente Z, Komoly S, Beyer C. 17betaestradiol and progesterone prevent cuprizone provoked demyelination of corpus callosum in male mice. Glia 2009; 57: 807-14.

78. Hussain R, El-Etr M, Gaci O, Rakotomamonjy J, Macklin WB, Kumar N, Sitruk-Ware R, Schumacher M, Ghoumari AM. Progesterone and Nestorone facilitate axon remyelination: a role for progesterone receptors. Endocrinology 2011; 152: 3820-31.

79.Rettberg JR, Yao J, Brinton RD. Estrogen: a master regulator of bioenergetic systems in the brain and body. Frontiers in neuroendocrinology 2014; 35: 8-30.

80.Andrabi SS, Parvez S, Tabassum H. Progesterone induces neuroprotection following reperfusionpromoted mitochondrial dysfunction after focal cerebral ischemia in rats. Disease models \& mechanisms 2017; 10: 787-96.

81.Taylor LC, Gilmore W, Ting JP, Matsushima GK. Cuprizone induces similar demyelination in male and female C57BL/6 mice and results in disruption of the estrous cycle. J Neurosci Res 2010; 88: 391402.

82.Xue XT, Kou XX, Li CS, Bi RY, Meng Z, Wang XD, Zhou YH, Gan YH. Progesterone attenuates temporomandibular joint inflammation through inhibition of NF-kappaB pathway in ovariectomized rats. Scientific reports 2017; 7: 15334.

83.Aryanpour R, Pasbakhsh P, Zibara K, Namjoo Z, Beigi Boroujeni F, Shahbeigi S, Kashani IR, Beyer C, Zendehdel A. Progesterone therapy induces an M1 to M2 switch in microglia phenotype and suppresses NLRP3 inflammasome in a cuprizone-induced demyelination mouse model. International immunopharmacology 2017; 51: 131-9.

84.Skripuletz T, Hackstette D, Bauer K, Gudi V, Pul R, Voss E, Berger K, Kipp M, Baumgartner W, Stangel $M$. Astrocytes regulate myelin clearance through recruitment of microglia during cuprizoneinduced demyelination. Brain : a journal of neurology 2013; 136: 147-67.

This article is protected by copyright. All rights reserved. 


\section{FIGURE LEGENDS}

Figure 1: Hippocampal myelin basic protein (MBP) expression and quantitative analysis of hippocampal glial reaction from CTRL, CPZ D and CPZ R mice .A: Level of MBP mRNA expressed as relative changes (mean $\pm S E M$ ) with control mRNA taken as 1.0. mRNA MBP was decreased in CPZ D mice $\left({ }^{*} p<0.05\right.$ vs. control) and increased in the CPZ R group (*** $p<0.001$ vs. CPZ $D ;{ }^{*} p<0.05$ vs. CTRL). B: MBP immunoreaction intensity was decreased in CPZ D ( ${ }^{*} p<0.05$ vs. CTRL) and recovered in CPZ R group $\left(* * * p<0.001\right.$ vs. CPZ D; ${ }^{*} p<0.05$ vs. CTRL). C: Photomicrographs taken from hippocampus of CTRL (left) CPZ D (middle) and CPZ R (right) showed decrease MBP immunoreaction in CPZ D group. Scale bar indicates $100 \mu \mathrm{m}$. D: Level of CD11B mRNA expressed as relative changes (mean $\pm \mathrm{SEM}$ ) with control mRNA taken as 1.0. CD11B mRNA was increased in CPZ D mice $\left({ }^{* *} p<0.01\right.$ vs. control) and decreased in CPZ R group $\left({ }^{*} p<0.05\right)$. E: Number of IBA1+ cells/area was increased in CPZ D ( ${ }^{* * *} p<0.001$ vs. CTRL) and decreased in CPZ R group ( ${ }^{* *} p<0.01$ vs. CPZ R; CTRL * $p<0.5$ vs. CPZ R). F: Photomicrographs taken from hippocampus of CTRL (left), CPZ D (middle) and CPZ R (right) showed increased IBA1+ cells density in CPZ D group. Scale bar indicates $50 \mu \mathrm{m}$. G: Number of astrocytes GFAP+/mm2 was increased in CPZ D group ( ${ }^{* * *} p<0.001$ vs. CTRL) and decreased in CPZ R group ( ${ }^{*} p<0.05$ vs. CPZ R; CTRL ** $p<0.01$ vs. CPZ R).H: TNF $\alpha$ mRNA was increased in CPZ D mice (*** $p<0.001$ vs. control) and decreased in CPZ R group ( ${ }^{* *} p<0.01$; CTRL $* * p<0.01$ vs. CPZ R). Data obtained were analyzed by ANOVA followed by the Newman-Keuls test; $n=5$ animals per group.

Figure 2: Hippocampal neurosteroidogenic protein and enzymes in the three experimental groups. A: Levels of steroidogenic acute regulatory protein (StAR) mRNA were decreased in CPZ D mice (** $\mathrm{p}<0.01$ vs. control) and restored to CTRL levels in CPZ R group ( ${ }^{* *} p<0.01$ vs. CPZ D). B: StAR immunoreactive area in the CA3 region of the hippocampus was decreased in CPZ D and increased in CPZ R group ( ${ }^{*} p<0.5$ vs. CPZ D; NS vs. CTRL). C: Photomicrographs taken from hippocampal CA3 region of CTRL (left) CPZ D (middle) and CPZ R (right) showed decreased StAR immunoreactive area in CPZ D group. Scale bar indicates $75 \mu \mathrm{m}$. D: mRNA levels (mean +/- SEM) of mitochondrial proteins and microsomal neurosteroidogenic enzymes in the hippocampus. Levels of the voltage-dependent anion channel (VDAC) and translocator protein $18 \mathrm{~K}$ (TSPO) mRNA did not differ among CTRL, CPZ D and CPZ R groups although TSPO mRNA reached higher levels in CPZ D. Levels of mRNA for cholesterol-side chain cleavage enzyme (P450 scc) were decreased in CPZ D $\left({ }^{*} p<0.05\right)$ and increased in CPZ R ( $\left.{ }^{*} p<0.05\right)$. The last group was not different from controls ( $\left.p: N S\right)$.Variations of the mRNA of $3 \beta$-hydroxysteroid dehydrogense ( $3 \beta-H S D)$ did not differ significantly between control, CPZ D and CPZ R group. Levels of mRNA for $5 \alpha$-reductase were decreased in CPZ D $\left({ }^{* * *} p<0.001\right)$ and increased

This article is protected by copyright. All rights reserved. 
in CPZ R group (**p<0.01). The last group was not different from controls ( $\mathrm{p}: \mathrm{NS})$. Data obtained by ANOVA followed by Newman-Keuls tests, $n=5$ animals per group.

Figure 3: Myelin, glial reaction and neurosteroidogenic parameters in the neocortex. A1: Levels of MBP mRNA were decreased in CPZ D mice ( ${ }^{* *} p<0.01$ vs. control) and increased in the CPZ R group $(* * * p<0.001$ vs. CPZ D; p:NS vs. CTRL). A2: Immunoreactivity for MBP was decreased in CPZ D $(* * * p<0.001$ vs. CTRL) and increased in CPZ $R(* * p<0.01 ; C P Z R * p<0.5$ vs. CTRL). A3: Photomicrographs from neocortex of CTRL (left) CPZ D (middle) and CPZ R (right) showed decreased MBP immunoreaction in CPZ D group. Scale bar indicates $100 \mu \mathrm{m}$. B1: Quantitative data showed increased number of microglial cells per $\mathrm{mm} 2$ in CPZ $\mathrm{D}\left({ }^{* *} \mathrm{p}<0.01 \mathrm{vs}\right.$. CTRL) and decreased IBA1+cells in CPZ R ( ${ }^{*} p<0.5$ : $p$ : NS vs. CTRL). B2: The number of astrocytes GFAP+ was increased in CPZ D vs. CTRL $(* * * p<0.001)$ and decreased in CPZ R (***p<0.001; $p$ : NS vs. CTRL). B3: Levels of TNF $\alpha$ mRNA were increased in CPZ D mice (** $p<0.01$ vs. control) and decreased in CPZ R group ( $\left.{ }^{* *} p<0.01\right)$.C1C3: Levels of StAR, P450 scc and 5 $\alpha$-reductase mRNA were decreased in CPZ D mice ( ${ }^{*} p<0.05$ vs. control) and restored to CTRL levels in CPZ R group ( ${ }^{*} p<0.05$ for StAR and ${ }^{* *} p<0.01$ for P450 scc and $5 \alpha$-reductase vs. CPZ D).Data obtained were analyzed by ANOVA followed by the Newman-Keuls test, $\mathrm{n}=5$ mice per group.

Figure 4: Myelin, glial reaction and neurosteroidogenic parameters in the corpus callosum. A1: Levels of MBP mRNA were decreased in CPZ D mice ( ${ }^{*} p<0.5$ vs. control) and increased in the CPZ R group (**p<0.01 vs. CPZ D; $p$ : NS vs. CTRL). A2: Sudan Black staining was decreased in CPZ D $(* * p<0.01$ vs. CTRL) and increased in CPZ R $(* * * p<0.001 ; p$ : NS vs. CTRL). A3: Photomicrographs from corpus callosum of CTRL (left) CPZ D (middle) and CPZ R (right) showed loss of myelin stained with Sudan Black in the CPZ D group. Scale bar: $100 \mu \mathrm{m}$. B1: Quantitative data showed increased number of microglial cells / mm2 in CPZ D (***p<0.001 vs. CTRL) and decreased IBA+ cells in CPZ R $\left({ }^{* * *} p<0.001 ; \mathrm{CPZ} R{ }^{* *} p<0.01\right.$ vs. CTRL). B2: The number of astrocytes GFAP+ was increased in CPZ D vs. CTRL $\left({ }^{* * *} p<0.001\right)$ and decreased in CPZ R $\left({ }^{*} p<0.5\right.$; CPZ R $* * * p<0.001$ vs. CTRL). B3: Levels of TNF $\alpha$ mRNA was increased in CPZ D mice (*** $p<0.001 \mathrm{vs.} \mathrm{control)} \mathrm{and} \mathrm{remained} \mathrm{at} \mathrm{the} \mathrm{same} \mathrm{level} \mathrm{in}$ CPZ R group (NS vs. CPZ D). B4: Photomicrographs from the corpus callosum of CTRL (left), CPZ D (middle) and CPZ R (right) showed an intense glial reaction containing highly activated microglial cells in CPZ D group. Scale bar: 50 $\mu \mathrm{m}$. C1-C3: Levels of StAR, P450scc and $5 \alpha$-reductase mRNA were decreased in CPZ D mice ( ${ }^{*} p<0.05$ for StAR and $5 \alpha$-reductase; ${ }^{* * *} p<0.001$ for P450 scc vs. control) and remained low in CPZ R group for StAR and P450scc ( $p=N S$ vs. CPZ D). $5 \alpha$-reductase mRNA levels

This article is protected by copyright. All rights reserved. 
were increased in CPZ R mice ( ${ }^{*} p<0.05$ vs. CPZ D). Data obtained was analyzed by ANOVA followed by the Newman-Keuls test. $n=5$ mice per group

\section{Figure 5}

IBA1 immunofluorescence in brain regions and double-label immune localization of StAR with neuronal and glia markers. A-C: Photomicrographs of microglia in remyelinated group in neocortex, hippocampus and corpus callosum. 14 days after cuprizone removal, gray matter microglia adopts a resting state while corpus callosum microglial cells still show an activated phenotype with thick processes. Scale bar: $25 \mu \mathrm{m}$. D-F: Representative confocal images of CPZ-treated mice showed intense NeuN/StAR colocalization in cortex. Scale bar: $20 \mu \mathrm{m}$. G-I: In the cortex of cuprizone-treated mice, reactive astrocytes are double-labeled for GFAP and StAR (arrows). Scale bar: $20 \mu \mathrm{m}$. J-L: In the corpus callosum of cuprizone-treated mice, CC1+ oligodendrocytes do not express StAR immunoreactivity. Scale bar: $20 \mu \mathrm{m}$.

Table 1. Sequence of primers for the amplification of target genes and Cyclophilin B

\begin{tabular}{|l|l|l|l|}
\hline Gene & $\begin{array}{l}\text { Accesion } \\
\text { Number }\end{array}$ & $\begin{array}{l}\text { Primer } \\
\text { sense 5' } \mathbf{3}^{\prime}\end{array}$ & $\begin{array}{l}\text { Primer } \\
\text { antisense 5' } \mathbf{3}^{\prime}\end{array}$ \\
\hline Cyclophilin B & NM_001025612 & GTGGCAAGATCGAAGTGGAGAAAC & TAAAAATCAGGCCTGTGGAATGTG \\
\hline MBP & NM_001025100 & ATCCAAGTACCTGGCCACAG & CCTGTCACCGCTAAAGAAGC \\
\hline TNFa & NM_013693 & GAAAAGCAAGCAGCCAACCA & CGGATCATGCTTTCTGTGCTC \\
\hline CD11b & NM_008401 & AAACCACAGTCCCGCAGAGA & CGTGTTCACCAGCTGGCTTA \\
\hline StAR & NM_011485 & GAGCTCTCTGCTTGGTTCTAA & TTGAGTATGCCCAAGGCCTT \\
\hline
\end{tabular}

This article is protected by copyright. All rights reserved. 


\begin{tabular}{|l|l|l|l|}
\hline TSPO & NM_009775 & TGCAGAAACCCTCTTGGCATC & TGAAACCTCCCAGCTCTTTCC \\
\hline VDAC & NM_011694 & CTCCCACATACGCCGATCTT & GCCGTAGCCCTTGGTGAAG \\
\hline P450scc & NM_019779 & CCTATTCCGCTTTTCCTTTGAGTCC & CGCTCCCCAAATATAACACTGCTG \\
\hline 3ß-HSD & NM_008293 & TCTGAAAGGTACCCAGAACCTATTGG & TTGCTTGAACACAGGCCTCCA \\
\hline 5 $\alpha$-Reductase1 & NM_175283 & TGTTTCCTGACAGGCTTTGCCC & CCATGCCCACTAACCACAGGG \\
\hline
\end{tabular}

This article is protected by copyright. All rights reserved. 
A
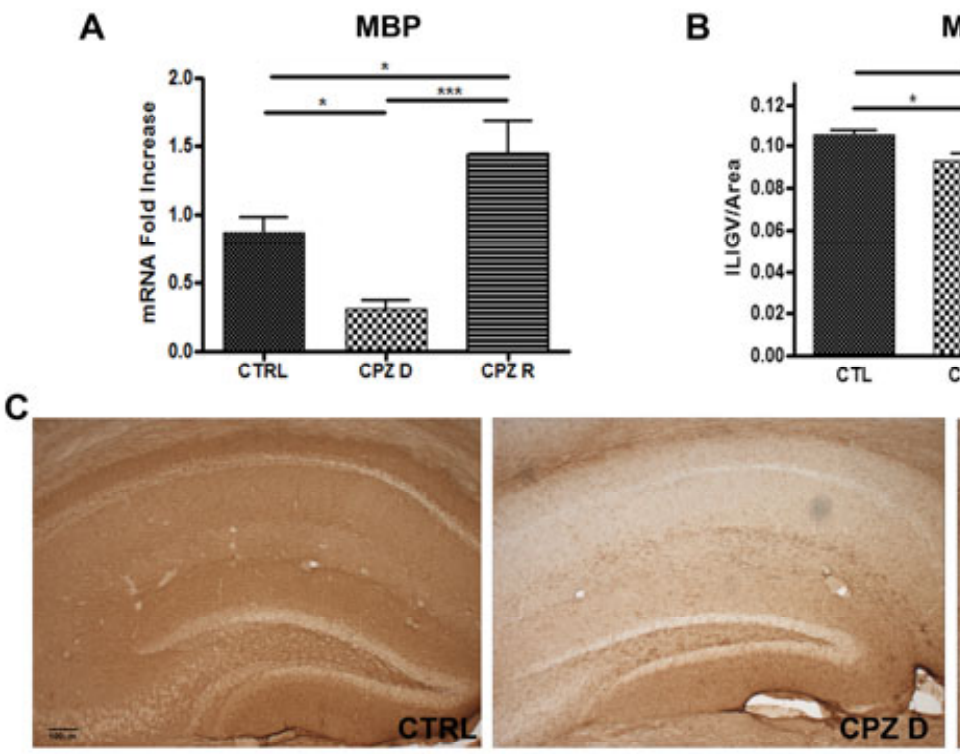

E

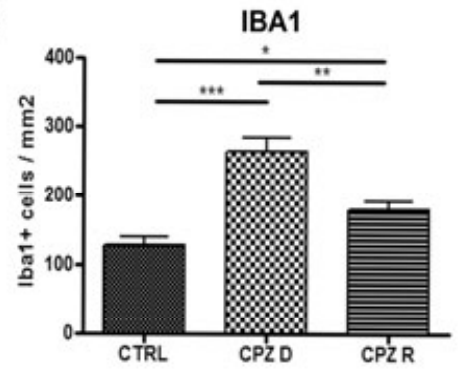

F
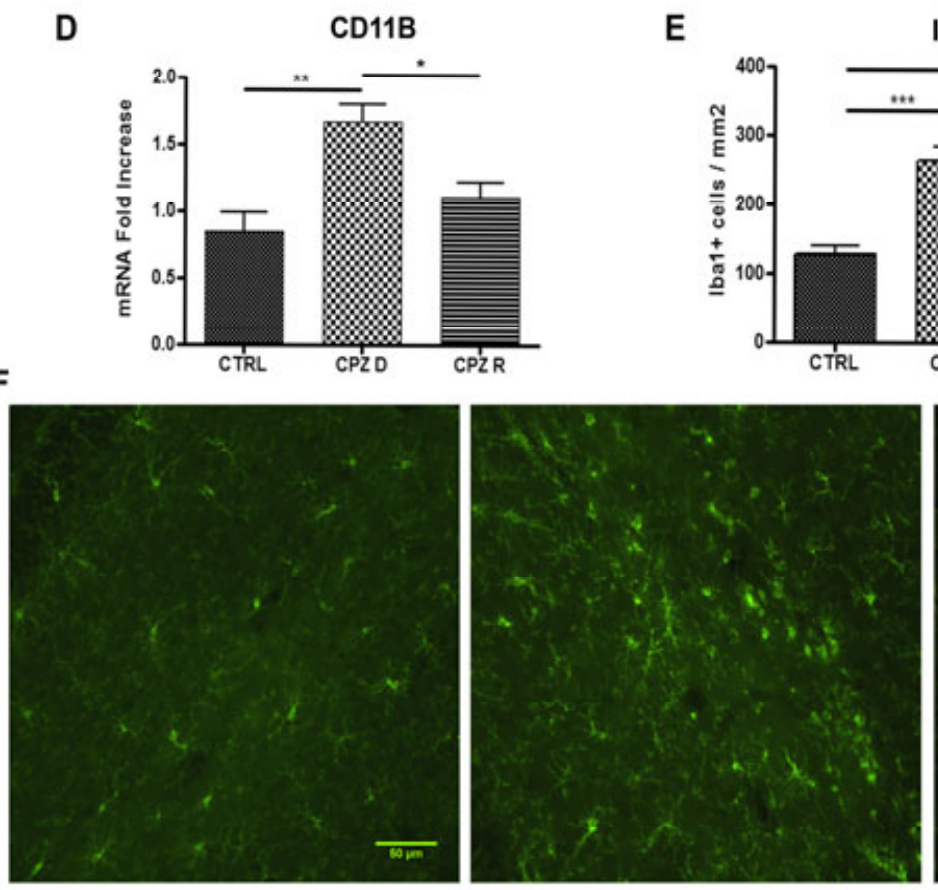

G

GFAP

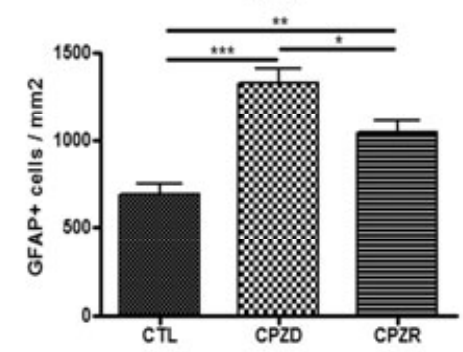

B

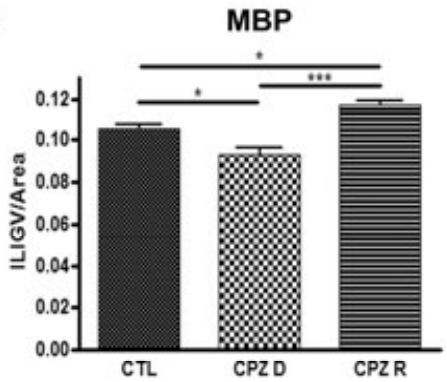

H

TNF $\alpha$

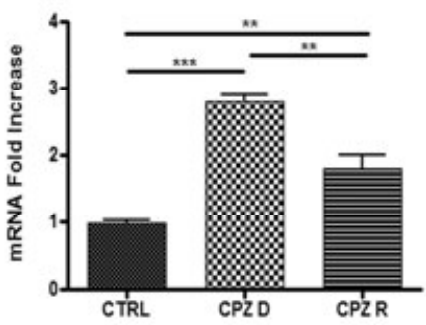

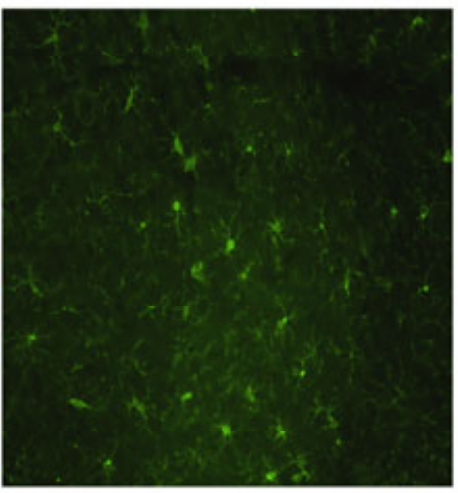

This article is protected by copyright. All rights reserved. 


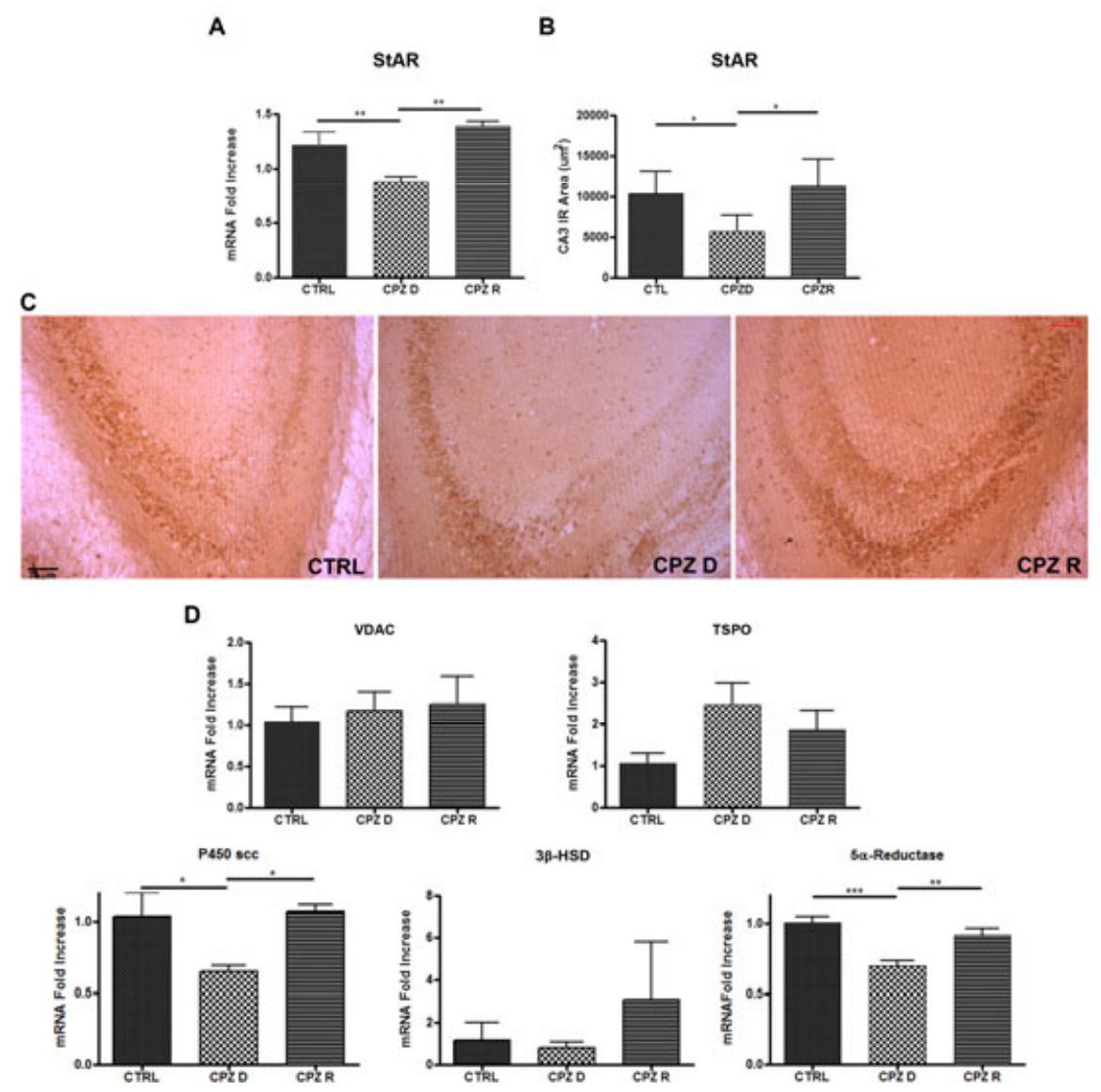

This article is protected by copyright. All rights reserved. 


\section{A-MYELIN BASIC PROTEIN}

A1

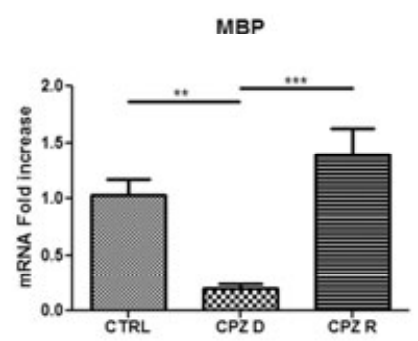

A2

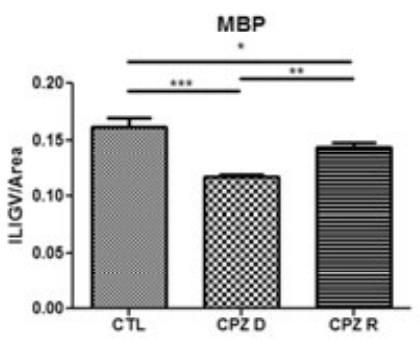

A3
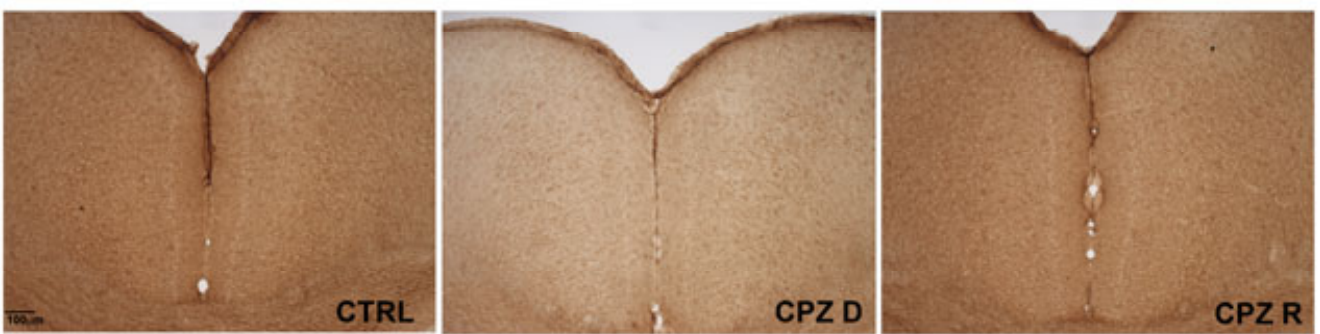

B-GLIAL CELL REACTIVITY

B1

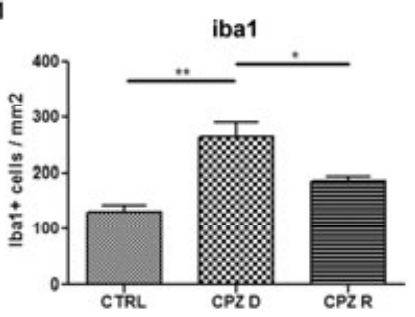

C-NEUROSTEROIDOGENESIS

C1

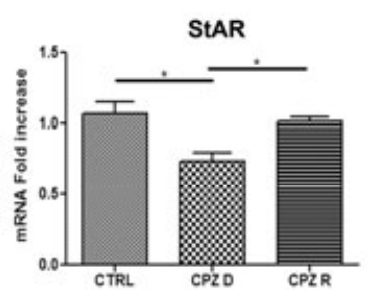

B2

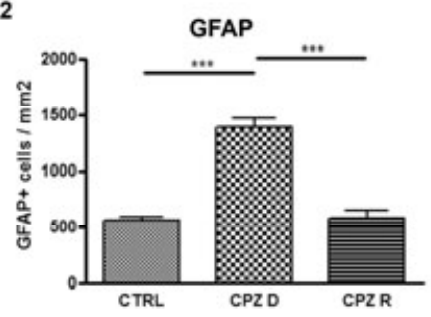

C2

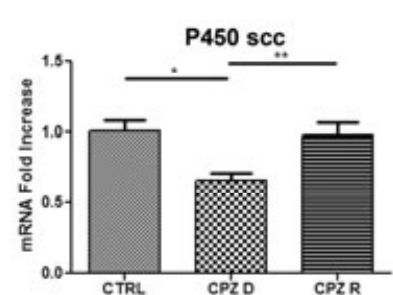

B3

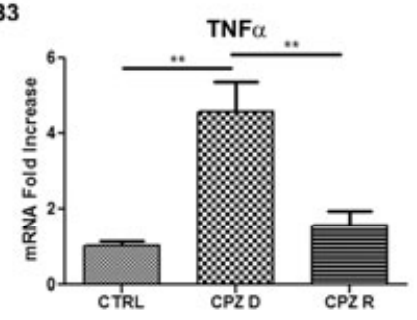

C3

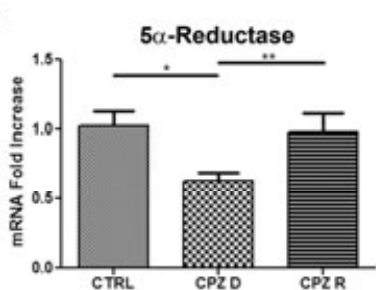

This article is protected by copyright. All rights reserved. 


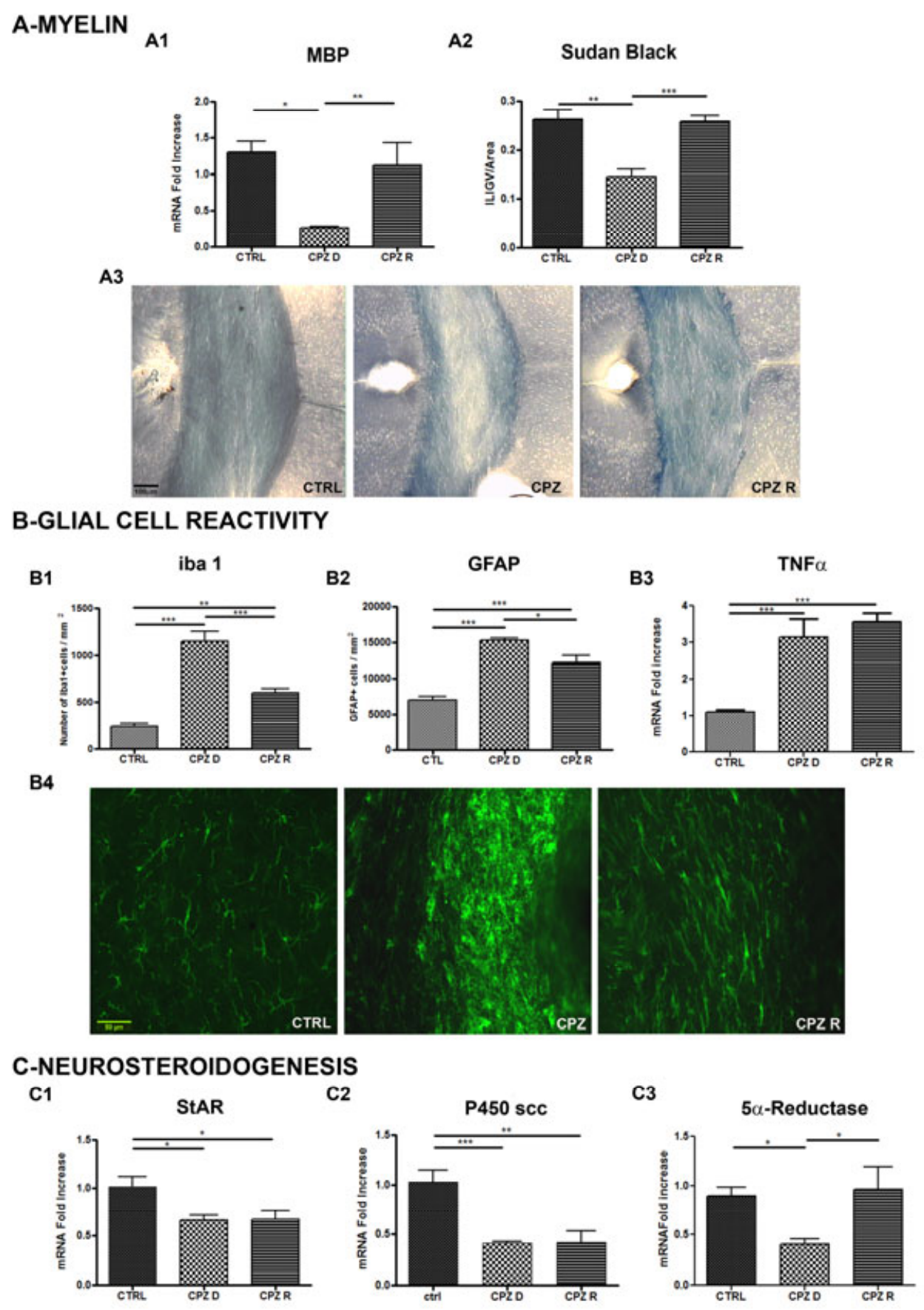

This article is protected by copyright. All rights reserved. 


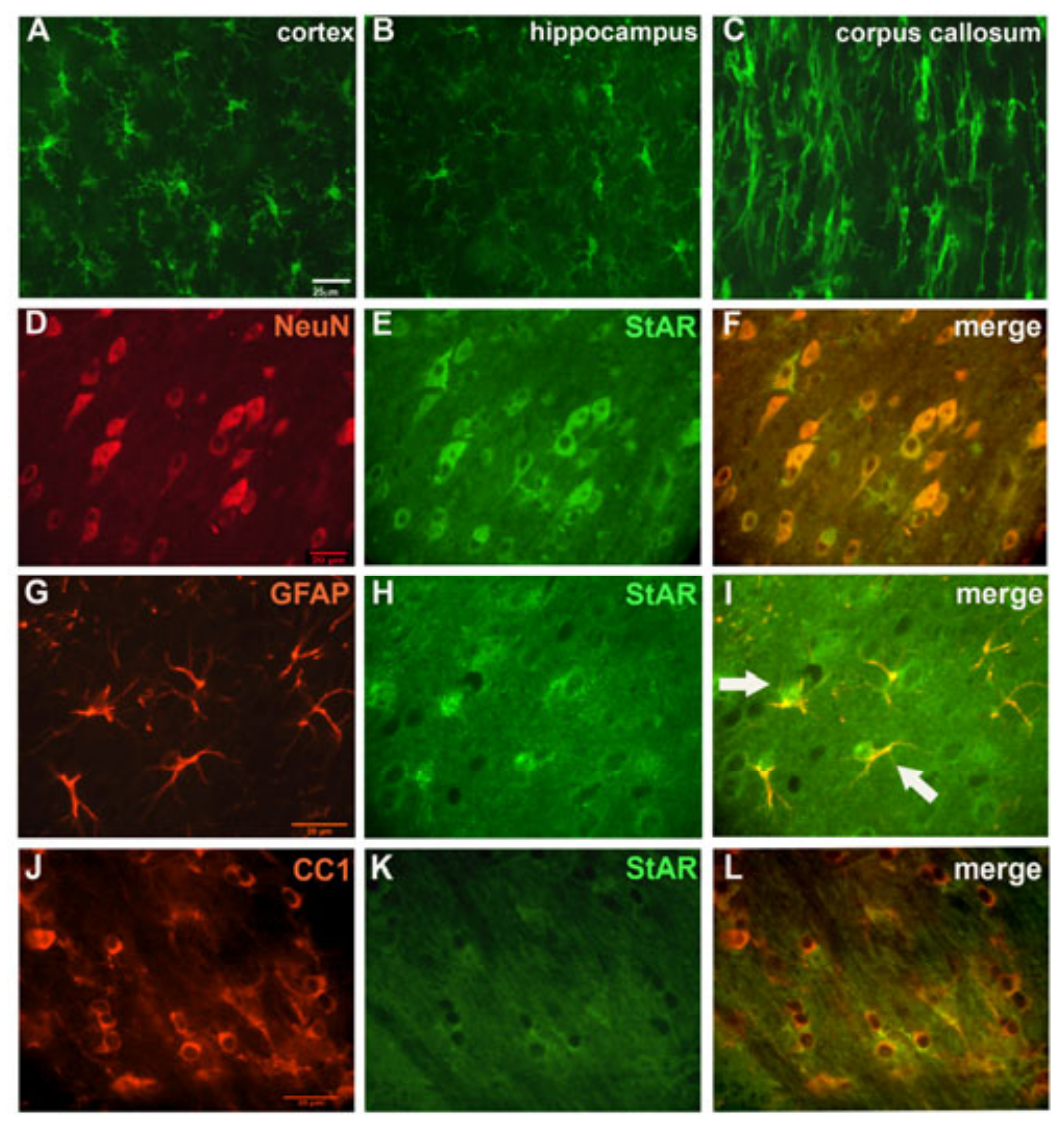

This article is protected by copyright. All rights reserved. 